\section{ZEW}

Zentrum für Europäische Wirtschaftsforschung GmbH

Centre for European Economic Research

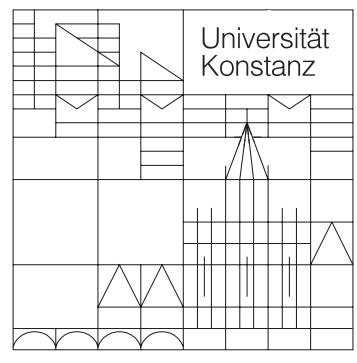

Rechts-, Wirtschafts- und Verwaltungswissenschaftliche Sektion

Fachbereich

Wirtschaftswissenschaften

Diskussionspapiere der DFG-

Forschergruppe (Nr.: 3468269275):

Heterogene Arbeit: Positive und Normative Aspekte der Qualifikationsstruktur der Arbeit

Michael Rauber,

Heinrich W. Ursprung

EVALUATION OF RESEARCHERS: A LIFE CYCLE ANALYSIS OF GERMAN ACADEMIC ECONOMISTS

Februar 2006 
Diskussionspapier der Forschergruppe (Nr.: 3468269275) "Heterogene Arbeit: Positive und Normative Aspekte der Qualifikationsstruktur der Arbeit"

Nr. 06/08, Februar 2006

\section{EVALUATION OF RESEARCHERS: A LIFE CYCLE ANALYSIS OF GERMAN ACADEMIC ECONOMISTS}

\section{Michael Rauber}

\author{
Fach D124 \\ 78457 Konstanz \\ Germany \\ mail: Michael.Rauber@uni-konstanz.de
}

\section{Heinrich W. Ursprung}

\author{
Fach D 124 \\ 78457 Konstanz \\ Germany \\ mail : Heinrich.Ursprung@uni-konstanz.de \\ phone : +49 7531-88-2332 \\ fax : $+49-7531-88-3130$
}

\section{Zusammenfassung:}

In this paper we ague that any meaningful bibliometric evaluation of researchers needs to take into account that research productivity follows distinct life cycles. Using an encompassing data set portraying the research behavior of German academic economists, we first show that research productivity crucially depends on career age and vintage. Based on the identified effects, we develop a simple formula that shows how a researcher's performance compares to that of his or her peers. This kind of information may serve as an input for performance-related remuneration and track-record based allocation of research grants. We then go on to investigate the persistence of individual productivity. The Persistence issue is of special importance in the academic labor market because of the irrevocable nature of tenure. Finally, we show how life cycle considerations can be used in evaluations of university departments in order to render the resulting rankings insensitive to the age structure of the evaluated faculties.

JEL Klassifikation

Schlüsselwörter Download/Reference :
: A11, A14, J24, J41, M 51

: research productivity, performance evaluation, life cycles, rankings

: http://www.wiwi.uni-konstanz.de/forschergruppewiwi/ 


\title{
EVALUATION OF RESEARCHERS: A LIFE CYCLE ANALYSIS OF GERMAN ACADEMIC ECONOMISTS
}

\author{
Michael Rauber* \\ Heinrich W. Ursprung* \\ February 6, 2005 \\ Working Paper Version
}

\begin{abstract}
In this paper we ague that any meaningful bibliometric evaluation of researchers needs to take into account that research productivity follows distinct life cycles. Using an encompassing data set portraying the research behavior of German academic economists, we first show that research productivity crucially depends on career age and vintage. Based on the identified effects, we develop a simple formula that shows how a researcher's performance compares to that of his or her peers. This kind of information may serve as an input for performance-related remuneration and track-record based allocation of research grants. We then go on to investigate the persistence of individual productivity. The Persistence issue is of special importance in the academic labor market because of the irrevocable nature of tenure. Finally, we show how life cycle considerations can be used in evaluations of university departments in order to render the resulting rankings insensitive to the age structure of the evaluated faculties.
\end{abstract}

JEL Classification: A11, A14, J24, J41, M 51

Keywords: research productivity, performance evaluation, life cycles, rankings

We thank Peter Egger, Werner Güth and Paula Stephens for helpful comments, and Robert Hofmeister and Philipp Stützle for valuable research assistance.

* Department of Economics, University of Konstanz, Box D-138, 78457 Konstanz, Germany Email: Michael.Rauber@uni-konstanz.de, Heinrich.Ursprung@uni-konstanz.de 


\section{Evaluation of researchers: A life cycle analysis of German academic economists}

\section{Introduction}

Evaluations compare certain features of a person with the features observed in a group of peers. A worthwhile evaluation needs to explicitly define the relevant comparison group and to make a case for the employed choice. In many cases, the contemporaries of the person to be evaluated represent the relevant peer group, the best example being the standard IQ test whose name even refers to the fact that intelligence is measured in relation to some denominator, which is, of course, the respective person's age. In sports, where evaluation almost represents the raison d'être, it is also quite common to compare contestants of the same age group, but other comparison groups, based, for example, on body weight or professional status, are also widely employed.

Research evaluations that are based on scientometric methods are still surrounded by a touch of controversy. Nevertheless, it is generally accepted that reasonable scientometric evaluations need to focus on narrowly defined disciplines ${ }^{1}$ how the disciplines should be delineated is, of course, another matter. Many scientometric studies are, moreover, restricted to specific geographic regions and types of institutions. Apart from these public-domain characteristics, the relevant peer group is also defined by personal characteristics, arguably the most important one being the researcher's age. ${ }^{2}$

Age features two distinct dimensions that are relevant in the evaluation context: vintage and career age. Both of these dimensions are liable to have a strong impact on research productivity because research production, maybe more than any other production

\footnotetext{
${ }^{1}$ The much publicized "Shanghai" ranking does, for example, not meet this requirement.

${ }^{2}$ Another often investigated characteristic is, of course, gender.
} 
process, heavily relies on human capital that is determined, on the one hand, by the initial endowment (i.e. by ability and initial training) and, on the other hand, by experience and obsolescence of knowledge. Since initial training (graduate education) is related to the age cohort, whereas experience and obsolescence of knowledge are related to career age, both of these age dimensions represent personal characteristics that are associated with generally recognized peer groups (class of 2005, assistant professors in their sixth year, etc).

Precisely because life-cycle and vintage effects are liable to influence any researcher's productivity, research evaluations which are undertaken to implement incentive-compatible managerial reward or penalty schemes, need to take these age dimensions into account. In principle, this statement is not controversial. Tenure and promotion committees have always compared the track records of the applicants with precedents. Alternatively, they have judged whether the track records are compatible with an established policy or standard. These standards, however, have evolved over time by investigating research oeuvres of applicants who, by the very fact that they aspired to take a certain career step, constitute a peer group defined by career age. Decisions with respect to performance-related pay have likewise been based on comparisons of track records. Since remuneration, unlike tenure and rank, does not represent a time-invariant prize, the applicant's age at the time of the application, i.e. his or her cohort or vintage, is always implicitly taken into account by the responsible authorities.

Even though of great importance for management decisions, studies dealing with the evaluation of economic research have hitherto rather neglected the age dimensions. This neglect applies especially to studies that evaluate entire groups of researchers, for example university departments or research institutes. An exception is the ranking study 
by Combes and Linnemer (2003) that was commissioned by the European Economic Association. These authors, who rank 600 economic research institutions from 14 European countries, present, among others, one research-productivity index that takes the respective researcher's career age into account. Even though the employed method of normalization with respect to career age is purely ad hoc, and the career age of the economists is estimated by rule of thumb, this study is groundbreaking because it spells out the demands that high-quality rankings should meet.

The available literature on life cycles in research productivity is oddly disconnected from the evaluation issue. The studies investigating life cycles are usually motivated by Gary Becker's human capital theory that predicts that investment in human capital decreases over the life cycle, thereby generating hump-shaped individual life cycles in labor productivity and earnings. Some scholars have extended the human capital approach to analyze the processes which are specific to research production. Others have used the standard human capital approach in order to guide their attempts to empirically identify the determinants of labor productivity; these scholars focus on research production mainly because measuring research productivity is, in many respects, easier than measuring labor productivity in other fields. The AER paper by Levin and Stephan (1991) followed both of these routes and was instrumental in kicking off the field that is now known as the economics of science.

Surprisingly few studies on research productivity were written by economists or investigate the economics profession. This has already been deplored by Paula Stephan in her (1996) JEL survey. Recent work on the economics profession include Kenny and Studley (1996), Oster and Hamermesh (1998) and Baser and Pema (2004) whose empirical results are compatible with a hump-shaped progression of individual research 
productivity over the life cycle as hypothesized by Becker's human capital theory. Goodwin and Sauer (1995), on the other hand, who do not clamp the life cycle in the Procrustes bed of a quadratic specification, identify a bi-modal life cycle. Hutchinson and Zivney (1995) and Hartley et al. (2001) do not find any evidence supportive of the standard life cycle hypothesis at all.

Among the many considerable econometric problems that arise when estimating life-cycles in research productivity, the most challenging one arguably consists of separating career age and cohort effects, an endeavor that is confounded by the fact that publication behavior has changed over time. In order to estimate life cycle and cohort effects separately, an extensive panel data set comprising many cohorts is indispensable, otherwise the potentially considerable cohort-specific influences cannot be estimated, and the resulting estimates of the life cycle pattern will be biased. ${ }^{3}$ It is conceivable that, because of these econometric problems, the empirical evidence with respect to cohort effects is somewhat elusive. Basar and Pema (2004) do not find any cohort effects at all, and Goodwin and Sauer (1995) report only marginally significant effects that are tainted since they may well reflect the fact that the members of the analyzed cohorts differ in age, implying that the older cohorts are composed of academic survivors and thus liable to have been more productive on the average.

The identification problem becomes even more challenging if one acknowledges that the publication behavior of economists has changed over time. Even if these changes have been relatively small, they may become significant in the course of a time period that allows estimating cohort effects. Since, however, career time, historical time and

\footnotetext{
${ }^{3}$ Cohort-specific influences refer, for example, to the knowledge base incurred during graduate education, the rate of obsolescence, access to resources, opportunities provided by the socioeconomic environment, and modes of behavior imprinted on the fledgling scientists. See Stephan (1996), pp 1216-7.
} 
cohort affiliation depend on each other in a linear manner (career time $=$ historical time cohort "birth" year), only two out of the three effects can be estimated subject to some assumption about the development of the third one. This is the reason why all estimates of life cycle and cohort effects on research productivity need to be interpreted with some caution. $^{4}$

This paper presents a new data set that describes the research behavior of German academic economists. The ultimate objective of studying research behavior is to help in developing workable management instruments for universities. We measure research productivity with the help of a standard bibliometric method based on weighted journal publications. We do not consider citations because citation counts are hard to incorporate in incentive-compatible research-evaluation schemes for three reasons: (1) citations are susceptible to manipulation (citation cartels), (2) only a small percentage of economic journal articles are cited sufficiently often to serve as a non-random indicator, and (3) the only established data base that allows citation analyses, the Social Sciences Citation Index, works with a relatively small sample of journals that reflects historical coincidences.

The paper unfolds as follows. In the next section we present our data set and in section 3 we describe the heterogeneity of research production with respect to both age dimensions (career age and cohort affiliation). Our investigation of heterogeneity culminates in the presentation of a simple formula that translates any German economist's research oeuvre into a ranking vis-à-vis his or her peers. Section 4 presents some life cycle regressions. Since tenure represents the arguably most important special feature of the academic labor market, we analyze, in section 5, the persistence of

\footnotetext{
${ }^{4}$ For a detailed exposition of the econometric methods that have been proposed to identify age, cohort, and period effects on individual research productivity, see Hall et al. (2005).
} 
individual research productivity in order to assess at what career stage promotion to a tenured position is justifiable. In section 6, we turn to evaluations of whole research units (German economics departments) and present some rankings that take the age dimension into account.

\section{The data set}

Most studies on research productivity over the life cycle employ a sample of scientists who are relatively active in research. The rationale for this approach is twofold. On the one hand, the behavior of choice researchers is better documented than that of less active ones. On the other hand, the standard econometric methods are better suited to process steady streams of activities than time series with many periods of inactivity. Since it is our intention to develop an evaluation scheme for all kinds of scientists, we did not follow this restricted approach and compiled a dataset that compromises, in principle, all academic economists currently working in Germany.

Since we use the EconLit data base, the American Economic Association's electronic bibliography of economic literature, we had to restrict ourselves to economists who received their doctoral degree at the earliest in 1969, the first year covered by EconLit. Considering that German academic economists receive their doctoral degrees when they are about 30 years old, this implies that the oldest economists in our data set were about 65 years old in 2004, the last year covered in our study. For these economists, we thus have complete life cycles. For the younger ones, the available life cycle becomes, of course, increasingly shorter. The shortest life cycles that we decided to consider have a length of six years which corresponds to a career age at which promising academic economists are granted tenure. We thus only consider scholars who received their 
doctoral degrees between 1969 and 1998 and who were employed at a German university in the year 2004 or have retired from such a position shortly before.

On the basis of these restrictions we have analyzed the publication records of more than 600 economists. To be more precise, our data set is comprised of all EconLitlisted journal publications authored or co-authored by the economists included in our sample. ${ }^{5,6}$ To be sure, bibliometric studies that are restricted to journal publications are not immune to criticism. However, the pattern of cross-citations between journal articles, articles published in edited volumes, and monographs, reveals that the principal outlets of research results in economics are the learned journals. This judgment is also in line with a recent study by Hartley et al. (2001) on economists' publication patterns in the US. The ramifications of the second restriction employed are somewhat ambivalent. Evaluating only the set of journals referenced in EconLit excludes journals whose scope is not aligned with the current mainstream of economic research, new economics journals, and journals that do not meet EconLit's quality standards. Whereas scope and timeliness are issues to be considered (scholars with peripheral or interdisciplinary specializations and scholars working on emerging fields may be underrated), exclusion because of insufficient quality does not appear to be an issue since the minimum quality standard set by EconLit is rather soft. In any event, using the EconLit data base has rather become the standard in bibliometric investigations, and Tom Coupé's tongue-in-cheek remark that

\footnotetext{
${ }^{5}$ For a few economists we have not been able to determine the year in which they received their doctoral degree. We have therefore omitted the records of these economists. On the other hand we have used records of economists whose doctorate does not fall into the observation period when we compare the oldest and youngest economists in our sample with their respective peers.

${ }^{6}$ Whenever EconLit reported "et al." we identified the hidden co-authors by tracing the article. This procedure does, of course, not guarantee that all publications in which one of our sample economists is a fourth or further co-author are properly linked. We are however confident that we thereby managed to mitigate EconLit's "et al." problem to a large extent.
} 
the current set of over 800 EconLit journals forms the economics literature is not too far off the mark. ${ }^{7}$

The quality standards set by the journals indexed in EconLit are of course quite diverse. Any study working with this data base therefore needs to capture quality differences in one way or another. If a reward scheme does not take these quality differences into account, the scientists would no longer attempt to produce research output of the highest possible quality but would rather shift their efforts towards producing results that are just about publishable in the journals with the softest quality standards. In other words: "Gresham's law of research evaluation" would see to it that mediocre research drives good research out of circulation.

A popular approach to controlling for journal quality is to use a subset of journals whose prime quality is uncontested. The ranking study by Kalaitzidakis et al. (2003), for example, followed this strategy. Restricting the journal set in this manner comes, however, at a significant cost. First of all, information especially about less accomplished scientists who do not publish in prime journals, is lost, with the consequence that reward schemes based on such a set of journals would not provide any incentives for this group of employees. A second drawback of restricting the journal set is that this strategy would prohibit us from investigating changes in research quality over the life cycle. For these reasons we decided to work with the whole set of journals indexed in EconLit, and to explicitly control for journal quality.

The evaluation of journal quality represents a field of its own. From the plethora of weighting schemes we chose the "CLpn" scheme proposed by Combes and Linnemer (2003) because it is based on the journals' relative (subjectively perceived) reputation and

\footnotetext{
${ }^{7}$ Cf. Coupé (2003), p. 1310.
} 
(objectively measured) impact, and thus appears to provide a well-balanced rating over the whole quality range. ${ }^{8}$ The CLpn-scheme converts each journal publication in standardized units of AER-page equivalents. The quality weight of the five top-tiered journals is normalized to unity. ${ }^{9}$ The sixteen second-tiered journals' imputed weight amounts to two thirds. Weights then decline in discrete steps (one half, one third, one sixth) down to the minimum weight of one twelfth. Our variable that measures research productivity of researcher i on an annual basis (year T) is defined as follows:

$$
\operatorname{CLpn}_{i}(T)=\sum_{k} \frac{p_{k(i)} w_{k(i)}}{n_{k(i)}}
$$

where $p_{k(i)}$ and $n_{k(i)}$ denote the number of pages and the number of authors of researcher i's publication $\mathrm{k}$, while $w_{k(i)}$ denotes the appropriate journal quality weight. The CLpn-index thus not only controls for quality but also for the number of authors and the length of the journal articles. ${ }^{10}$

In order to obtain comparable individual life cycles of research productivity, we merged the annual records of individual research productivity with the year in which the respective researcher obtained the doctoral degree, i.e. we align the individual life cycles by this reference year. Even though we let the academic career start with the conferment of the doctoral degree, this does not mean that we do not consider the research output generated in the pre-PhD period.

Our data set also contains some coarse information about the included economists' field of specialization, and we also documented the researchers' gender.

\footnotetext{
${ }^{8}$ One disadvantage of this method is that journal quality is kept constant over the period of investigation that covers, after all, a time-span of 36 years.

${ }^{9}$ The top-tiered journals are the American Economic Review, Econometrica, the Journal of Political Economy, the Quarterly Journal of Economics and the Review of Economic Studies. ${ }^{10}$ We did not, however, take into account that the number of words per page differs across journals.
} 
Only about $7.5 \%$ of our academic economists are women. $15 \%$ of the economists in our sample specialize in microeconomics, $26 \%$ in macroeconomics, $34 \%$ in public economics and $16 \%$ in econometrics. Economists who could not be assigned to any one of these fields were assigned to the field OTHER.

\section{Describing the landscape of German academic research in economics}

An evenhanded evaluation of a scientist's research performance presupposes information about the performance of his or her peers. In order to obtain a first impression of the size and distribution of the oeuvres of German academic economists, we cumulate the annual research outputs defined in equation (1) from career year -5 until career year $t$, where 0 denotes the year in which the economists were granted their doctoral degrees,

$$
R_{i}(t)=\sum_{T=-5}^{t} C L p n_{i}(T)
$$

and then compute for all career ages $\mathrm{t}$ the borderline values of $\mathrm{R}$ for the following percentiles: $25 \%, 50 \%, 80 \%$, and $90 \%$. The resulting information is depicted in Figure 1 .

Averaging over all economists in our sample we observe, first of all, that the oeuvre of the median researcher is quite modest. During his whole career the median German economist does not manage to produce more than 10 AER-equivalent pages. Assuming that all of his research has been published in journals belonging to the lowest quality tier, this implies that the median economist publishes about 6 journal articles (20 pages each, without coauthors) during his research career, i.e. one article every six years. Second, Figure 1 reveals that the distribution of the individual research oeuvres is skewed to the right and exhibits a large variation. These characteristics do, of course, not come as a surprise. Rather, they constitute stylized facts that have transpired from many related 
studies. ${ }^{11}$ More interesting is the fact that the percentile borderlines are not monotonous and exhibit a marked "overall" concavity. The violation of monotonicity of the stock variable $\mathrm{R}$ is not as puzzling as it might appear at first sight; it simply reflects cohort effects in our unbalanced panel. If research productivity increases dramatically across cohorts, the stock of the scientists at a young career age (measured across all cohorts) may well be larger than the stock of the scientists at an older career age (measured across only those cohorts who have reached this career age). The concavity of the percentile borderlines admits two interpretations: it may either reflect decreasing marginal productivity over the life cycle or it may again represent an artifact of cohort effects in our unbalanced panel.

In order to discriminate between the decreasing marginal productivity interpretation and the interpretation that presumes cohort effects, we present in Table 2 the size and distribution of the career-time oeuvres of different cohorts. For that purpose, we divided our sample of economists into five cohorts, each comprising six age groups. The oldest cohort comprises the age groups 1969-1974, and the youngest one comprises the age groups 1993-1998. The members of the oldest cohort thus look back on a career of at least 30 years, while the members of the youngest one have had a career of at least six years. The percentile borderlines are now monotonous, indicating that vintage effects within the cohorts are relatively small.

Two interesting insights transpire from our data as represented in Figure 2. First, eyeballing of the cohort-specific percentile borderlines does not suggest any pronounced concavity. An S-shaped life cycle productivity pattern supporting the factors portrayed by the standard human capital model thus cannot be identified, at least not at the aggregate

\footnotetext{
${ }^{11}$ The highly skewed nature of publication was first observed by Lotka in 1926 in a study on physics journals (cf. Stephan, 1996, p. 1203).
} 
level. To shed some more light on this issue, we will, therefore, further investigate our economists' life cycles with the help of micro-econometric methods in Section 4. The second feature that emerges from Figure 2 is more conclusive. The German economics profession is characterized by striking cohort effects in research productivity: the percentile borderlines become increasingly steeper for younger cohorts. The increase in cohort-specific research productivity is emphasized in panel (f) in which the $80 \%$-lines of the five cohorts are superimposed. This representation shows that it took an economist who tops $80 \%$ of his peers in the oldest cohort about 18 years to accumulate an oeuvre of 20 AER-equivalent pages, whereas a top- $80 \%$ economist of the second cohort managed to do so in 12 years. This time span is reduced to 8 and 4.5 years for the two following cohorts, respectively, and the top- $80 \%$ economist of the youngest cohort only needs 3.5 years to produce 20 -AER equivalent pages.

From our data set we can extract information that is directly relevant for the evaluation of individual researchers. In particular, we can assign each economist a peerspecific performance rank at each point of career time. This kind of information is of prime importance for a university management that wants to pursue a rational performance-related remuneration policy. Information about the standing of individual researchers vis-à-vis their peers is, moreover, a prerequisite for department rankings that are insensitive to the age structure of the evaluated faculties. We will turn to this issue in section 6 . Whole career profiles in terms of relative performance are, finally, of vital importance to assess the persistence of research performance. The crucial question in this context is whether it is possible to forecast a scientist's research performance from his track record, and if so, at which stage of a scientist's career such forecasts are sufficiently accurate to serve as a basis for management decisions such as granting tenure or awarding 
substantial research grants. The persistence issue will be dealt with in section 5 . Here we will follow up the first issue and ask ourselves how the information about the current cohort-specific ranking of individual economists can be condensed in such a way that it can serve as a simple management information device.

To do so, we consider the standard situation faced by a university management or a research foundation that would like to assess an economist's relative research standing in the German academic profession. Usually, the evaluator has only access to this person's CV including publication list. With the help of the publication list and the journal weights from Combes and Linnemer (2003) it is easy enough to compute via equations (1) and (2) the accumulated research output R at the end of the year 2004. Dividing this output $\mathrm{R}$ by the adjusted career age $\tau(\tau=2010-\mathrm{Y}$, where $\mathrm{Y}$ denotes the year in which the evaluated economist received his or her doctoral degree) yields the average research productivity $\mathrm{P} .{ }^{12}$ How does the average research productivity $\mathrm{P}$ of an economist translate into a ranking vis-à-vis his or her peers? Since the relative research standing depends on the average research productivity as well as on the cohort age of the person to be evaluated, we are seeking a formula of the form $\mathrm{S}=\mathrm{f}(\mathrm{P}, \mathrm{Y})$, where $\mathrm{S}$ denotes the evaluated economist's relative research standing in percentiles. ${ }^{13}$ Regressing S on Y and $\mathrm{P}$ yields the following formula: ${ }^{14}$

\footnotetext{
${ }^{12}$ We let the productive time of a researcher start five years before the doctorate. Since the doctorate takes place in career year $\mathrm{t}=0$, the adjusted career age $\tau=2004-\mathrm{Y}+6=2010-\mathrm{Y}$.

${ }^{13}$ The relevant peer group always consists of five age groups (the age group of the person to be evaluated and the four neighboring age groups).

${ }^{14}$ Note that the estimation was carried out using OLS. We are aware of the problems using OLS for a bounded dependent variable. However, since this is essentially an exercise in descriptive statistics we stick to OLS.
} 


$$
S=18.3-\frac{9.2}{1000} \cdot Y+0.55 \cdot \sqrt[3]{P} \cdot 15
$$

The residuals of our regression are depicted in Figure 3. Positive residuals imply that the true rank is underestimated, whereas in case of a negative residual the true rank is overestimated. For evaluation purposes, the negative residuals (overestimation) clearly present the relevant downward risk. Since the distribution of residuals resembles a normal distribution with a standard deviation of 0.077 , the probability of overestimating a candidate by 10 percentiles is about $10 \%$. This appears to be a risk well worth taking in a situation in which the alternative is to rely on peer evaluations and recommendations that are notoriously biased.

\section{A micro-econometric investigation of life cycle productivities}

The empirical evidence presented in the previous section suggests that life cycles in economic research productivity are rather flat. This evidence refers, however, to highly aggregated data. In order to do justice to the heterogeneity in our population of economists we exploit the micro-structure of our data set in the following analysis, i.e. we regress individual research productivity not only on career-time and cohort membership, but also on the field of specialization, on a gender dummy variable, and on a measure of ability. Following Goodwin and Sauer (1995), we rank the researchers according to their cohort-specific average life-time productivity. We then define quintile ranks within the distribution for each three-year cohort and assign each researcher the appropriate ability rank.

\footnotetext{
${ }^{15}$ Our formula approximates our regression result which explains $93 \%$ of the variance of $\mathrm{S}$; the more sophisticated version has as the following appearance: $\mathrm{S}=\min \left(\max \left(18.285-0.0092 * \mathrm{Y}+0.5535 \mathrm{P}^{1 / 3}, 0\right), 1\right)$.
} 
Since about three quarters of our observations of the dependent variable (research productivity of economist $\mathrm{i}$ in year $\mathrm{t}$ ) are zeroes, we cannot apply OLS. To accommodate this high degree of censoring we use a hurdle model, i.e. we allow the decision making process to be (potentially) more complex than the one captured by a standard Tobit model. ${ }^{16}$ The first part (being active) is portrayed with a Probit model, whereas the distribution of the positive counts is modeled with the help of a truncated Negative Binomial model since the observed density distribution of our dependent variable resembles the pattern of count data. ${ }^{17}$

The results of our regressions are summarized in Table 1. The two regressions presented in the first two columns focus on heterogeneity with respect to ability. In these regressions we not only include dummy variables for each ability rank, ${ }^{18}$ but also allow the life-cycle polynomials to differ across the ability ranks 5 (top researchers), 4 (accomplished researchers) and 1-3 (journeymen researchers). ${ }^{19}$ Figures $4 \mathrm{a}$ and $4 \mathrm{~b}$ visualize the fact that the time polynomials differ across ability ranks and that there are significant differences between the time polynomials of the Probit and NegBin part, thereby suggesting different forces governing the two respective processes. Our results indicate that the top-researchers manage to increase their publication incidence over time while their research productivity somewhat declines in the second half of their careers. It thus appears that the best researchers in the profession focus in the beginning of their

\footnotetext{
${ }^{16}$ For other estimation techniques, see the companion paper: Rauber and Ursprung (2005).

${ }^{17}$ This resemblance (spikes at steps of 1/12) emerges because the CLpn index is based on journal weights that are multiples of $1 / 12$. To arrive at proper count data we divided our CLpn variable by one twelfth and rounded to the next integer. The variable transformed in this manner can then, of course, be analyzed by using a count data model. One count can be interpreted as 1/12 of an AER equivalent page or one page in a journal of lowest quality.

${ }^{18}$ It is not surprising that the rank dummy variables are highly significant and that a higher rank is associated with higher research productivity.

${ }^{19}$ It was necessary to bundle the first three ranks together because of the high degree of censoring within these ranks. Nevertheless, we still allow for different intercepts for each rank.
} 
careers on fewer research projects (articles) but execute them with more effort which gives rise to higher quality (better journals) and more extensive results (longer articles), and all this is achieved with fewer co-authors. Later on in their careers these researchers get involved in more projects that are, however, executed with less effort. The two processes (number of projects and research effort put into each project) neutralize each other and, in conjunction, give rise to the flat life cycles in overall research productivity already observed. Decomposing our measure CLpn of research productivity and regressing average quality, article length, and number of co-authors on our explaining variables indeed shows that older economists work together with more collaborators (coauthors), write shorter articles, and publish in lower quality journals. Interestingly, however, top researchers manage to maintain quality much more than their less gifted peers. ${ }^{20}$

As compared to the top-researchers, the "accomplished" researchers' publication incidence and research productivity declines more sharply over their life cycles. These life cycles are thus better in line with the predictions of the human capital approach to explaining labor productivity. The "journeymen" researchers, finally, have rather flat and nondescript life cycles.

The coefficients of the cohort dummies, not surprisingly, increase over time. This result is consistent with the joint hypothesis of more productive younger cohorts and a constant historical time effects. We admit, however, that it is not inconceivable that our regressions somewhat overestimate the identified vintage effects since the gradual substitution process towards publishing research results mainly in journals may still have been at work, at least in the beginning of our period of observation. The estimated

\footnotetext{
${ }^{20}$ See our companion paper: Rauber and Ursprung (2005).
} 
coefficients of the gender dummy variable indicate that female economists publish significantly less than their male peers. This negative effect, however, arises from the fact that female academic economists seem to be more likely not to engage in research at all. If female economists decide to be active researchers, then they are just as productive as their male peers. Our field dummies, finally, show that researchers specializing in macroeconomics are less likely to be active researchers, and active micro-economists publish more than their peers. Even though these effects appear to be relatively small and fragile, it might be worthwhile to bear these field effects in mind when evaluating individual economists.

The standard Tobit regression presented in the third column of Table 1 focuses on heterogeneity with respect to cohort membership. As in the hurdle model, we allow the life cycle polynomials to differ, this time across our six cohorts. Figure 5 visualizes the cohort specific time polynomials. It can be seen with the naked eye that the shape of these life cycles differs across cohorts: younger cohorts have more hump-shaped life cycles than older cohorts. With respect to the other explaining variables nothing changes dramatically.

We thus arrive at the result that the life cycles of younger cohorts - as far as we can tell from the initial phases of these cycles - correspond more closely to the predictions of the standard human capital approach to explaining changes in labor productivity than the evidence we have for older economists. Various hypotheses lend themselves to explaining this result. The first and arguably most plausible one maintains that the academic environment has become increasingly more competitive over the last 35 years. In a more competitive work environment, employees who want to succeed are forced to optimize under the pertaining constraints. It is thus not surprising that their 
behavior more closely corresponds to the predictions of the human capital model that narrowly focuses on labor market incentives. An alternative hypothesis is that doctoral students of older cohorts have been exposed to different role models than the younger cohorts. This hypothesis relates to the preference formation process which works through sociological imprinting. The last hypothesis does not assume a change in preference formation but different preferences of the people who decide to pursue an academic career. Whether it is possible to empirically discriminate between the three hypotheses (that are, of course, not mutually exclusive), remains to be seen. ${ }^{21}$

\section{Persistence of research productivity}

The economics of science literature has clearly demonstrated that an academic scientist's research productivity has a noticeable influence on his or her labor market success. First of all, research productivity varies positively with pay (cf. Kenny and Studley, 1996, and Moore et al., 2001, for empirical evidence relating to the economics profession). A strong research record has, moreover, also a positive influence on the obtainable job status in terms of the employing university's reputation (cf. Grimes and Register, 1997, and Coupé et al., 2003), and scientists with strong research records are more likely to be granted tenure and to be promoted to higher academic ranks (cf. Coupé et al., 2003). Tenure and promotion to the highest level of the academic hierarchy may, on the other hand, have detrimental effects on research productivity because these types of upgrading are irrevocable and thus reduce incentives to work hard. Backes-Gellner and Schlinghoff (2004), for example, have shown that research productivity of German (business) economists increases before the only crucial career step (appointment to a professorship)

\footnotetext{
${ }^{21}$ See Frank and Schulze (2000) for an experimental design to test a related set of hypotheses.
} 
and is reduced afterwards. An early study on the impact of tenure that arrived at similar results for the United States is Bell and Seater (1978). ${ }^{22}$

Precisely because irrevocable career steps are liable to have a certain influence on research productivity, it is important to know at what stage of the academic career the research potential of a scientist can be assessed with reasonable accuracy and to what extent this potential is liable to be used in the post-tenure period. In other words, it is (from a managerial point of view) important to possess firm information on the persistence of individual research productivity. Inspection of our aggregate and individual data has already revealed that research productivity in our sample of economists is characterized by a great deal of persistence. In this section, we focus on the question whether the traditional American policy to grant, postpone, or decline tenure after a review period of six years does make sense in the light of our empirical evidence with respect to the predictability of research productivity. This question is of great relevance for the current discussion in Germany about how to best advance the new generation of academic scientists in order to catch up with the leading countries in the world. Many knowledgeable observers agree that young scientists have to wait too long to be promoted to a professorship in the German university system. On the average, the implicit probation period amounts to eight years (German economists obtain their doctoral degrees when they are about 30 years old and are, on the average, appointed to their first professorship at the age of 38). The objective of the investigation presented in this section is to inquire whether the review period could indeed be shortened without great loss in terms of evaluation accuracy.

\footnotetext{
${ }^{22}$ For a recent theoretical study of tenure and related incentive schemes in academia, see Dnes and Garoupa (2005).
} 
As compared to tenure-induced effects on research productivity, the optimal timing of the tenure decision has not found a great deal of attention in the scientometric literature dealing with the economics profession. A notable exception is the study by Hutchinson and Zivney (1995). These authors regress the average annual post-tenure productivity (measured in numbers of journal articles) on the pre-tenure oeuvre of economists using two hypothetical review periods, namely the standard six years and four years. Their regression analysis leads them to concur with Bell and Seater's (1978) conclusion based on cross-sectional data "that granting of tenure seems to have negative effects on individual publishing performance" (p. 614). "Yet, because the negative effect is so small numerically, 0.01 articles per year, our results indicate that publishers maintain essentially constant pre- and post-sixth-year rates of publication over their postdoctorate years. Moreover, shortening the review period from six years after the doctorate to four, relying upon our 1969-1979 doctorates, only slightly reduces the ability to predict future journal publication rates based on existing journal publication information while also producing almost constant pre- and post-fourth-year rates of publication" (Hutchinson and Zivney, 1995, p. 74).

In order to check whether the German economists' academic standing reached by their sixth year after the doctorate is a good indicator for their mid-career reputation (at the approximate age of 42 , i.e. in the twelfth year after the doctorate), we ranked all economists in our sample at career time $\mathrm{t}=6$ according to the size of their oeuvres in relation to a special five year cohort for each class. ${ }^{23}$ We then define quintile ranks and assigned each researcher the appropriate rank. Repeating this procedure for the career year $\mathrm{t}=12$, we arrived at the mid-career ranking of the same economists and were then

\footnotetext{
${ }^{23}$ Members of the class of 1981, for example, are ranked in the cohort comprising the classes of
} 1979 up to 1983. 
able to compute the probability of moving from one quintile rank to another within the observation period. These transition probabilities are shown separately for the older economists in our sample (classes of 1969 to 1980) and for the younger ones (classes of 1981 to 1992) in Table 2. Due to the inescapable problem of research-inactive scholars we had to group the first to quintiles together with the consequence that the probabilities in the columns do not add up to $100 \%$.

The results summarized in Table 2 once more show that research production is indeed characterized by a great deal of persistence. The probabilities on the main diagonal are substantially larger than the off-diagonal probabilities, implying that marked changes in the academic standing are low probability events. Table 2, in particular, shows that appointing a young professor with a reputation of a "top researcher" is a relatively safe bet these days: Only in about 14 out of one hundred cases does one end up with a colleague who is less than superb in six years time. The downward risk is thus very limited. On the other hand, appointing a professor with a bad publication record and hoping (perhaps based on hearsay) for the best, is nothing more than wishful thinking. The probability of a bottom group researcher making it in the first six years of his or her full professorship to the top $40 \%$ is nowadays not more than 4 out of $100 .^{24}$ Table 2 also documents that the research track record has become a better indicator of future research productivity over the years. The transition probabilities of the younger economists are more centered on the main diagonal than those of the older economists.

The evidence summarized in Table 2 documents that, currently, a six year review period provides ample evidence for an informed tenure decision. The question therefore

\footnotetext{
${ }^{24}$ Notice that the persistence documented in Table 2 is, of course, to some extent predicated by the question we ask, i.e. by the fact that we use stock data to measure reputation. Using flow data would certainly increase the inter-quintile transition probabilities.
} 
arises as to whether the German method of appointing professors (i.e. after an average review period of eight years) is indeed significantly superior in terms of avoiding bad appointments to justify the cost (especially the attendant loss of appeal to pursue an academic career). To investigate this question, we have computed the transition probabilities of the younger German economists also for hypothetical review periods of eight and four years. The results are summarized in Table 3. Given that we work with stock variables, it is not surprising that the predictions become somewhat sharper when using an eight instead of a six year review period, and somewhat more diffuse when using a four year period. More interesting is the fact that reducing the review period from the German standard of eight years to the American standard of six years does not appear to come at a great loss of information. Research excellence, in particular, can be detected after six years just as well as after eight years. In many cases of truly superior young scientists, a review period of four years may well be sufficiently long to make a reasonably safe appointment decision. Our conclusion is thus in line with the results derived for the United States by Hutchinson and Zivney.

\section{Some new rankings for German economics departments}

If one agrees that the evaluation of individual researchers should take career age and cohort affiliation into account, then these age dimensions should also be considered when ranking whole departments. After all, meaningful department rankings are supposed to reflect the research competence of its members and not the age structure of the departments' faculty. In this section we therefore present some rankings of German economics departments that reflect the life cycle dimension of the evaluated faculties. The objective is to demonstrate how, in principle, such rankings can be conceptualized 
and to show how rankings that incorporate life cycle information compare to traditional rankings that do not do so.

We decided to produce rankings that are comparable to the research rankings published by the Centrum für Hochschulentwicklung (CHE) because the CHE-rankings, even though criticized by an impressive number of knowledgeable observers of the German research landscape, nevertheless are quite influential. The reference groups of the CHE-rankings are the tenured professors of the respective departments. Whether this reference group constitutes a meaningful basis for an evaluation is questionable. Nevertheless we adopt here this approach in order to provide results that are easily comparable to an established German standard.

The rankings that are presented in Table 4 refer to 52 economics departments. All of these departments confer degrees in economics and belong to a German university; we thus do not consider economics departments of second-tier universities, the so-called universities of applied sciences.

One of the main (but little appreciated) challenges of current potential rankings as compared to work-done-at rankings consists in the identification of the respective faculty members. The CHE apparently believes that giving the departments an opportunity to comment on preliminary faculty and publication lists constitutes a sufficient measure of quality control. A cursory look at the faculty lists used by the CHE shows, however, that some of these lists are grossly at variance with a truthful representation. ${ }^{25}$ We therefore decided to base our rankings on a set of faculty lists

${ }^{25}$ According to the CHE, the department of economics of the University of Freiburg possesses 16 full professorships in economics. A cursory glance at the clearly laid out homepage of this department shows however that only nine out of these 16 professors are economists. Of the remaining seven persons, five are specializing in business administration and two in information sciences. In computing department averages of professorial research productivity, it is clearly of utmost importance to get the denominator right. The method used to measure research output and 
(presented in the appendix) that is based on the insider knowledge of a large number of German economics professors.

Our first ranking (see column A in Table 3) simply represents the mean of the individual research standings of the respective faculty members, where the individual research standing is defined via the percentile value of average life-time research productivity within a three years cohort comprising all economists who received their doctoral degrees in the same year as the evaluated individual or in a neighboring year. Since these overlapping three-year cohorts are rather small for some years, we also show a ranking based on cohorts of five years (column B). The rankings appear to be quite insensitive to the chosen cohort size: only three out the 52 ranked departments move by three ranks and one (Lüneburg, one of the two smallest departments with three professors) by four ranks across the two rankings. The two first rankings are thus very similar which is confirmed by a rank-correlation coefficient amounting to $99.6 \%$ (see Table 5).

As far as the top-ranked departments are concerned, the results of the first two rankings confirm, in essence, the results of earlier studies and the assessment of informed observers of the German economics profession. ${ }^{26}$ Somewhat surprising is perhaps the fact that the LMU Munich is only placed $9^{\text {th }} \cdot{ }^{27}$

The first two rankings do not take into account that the research standing of individual economists is sensitive to their respective field of specialization. As we have shown in section 4, the field of specialization has a statistically significant influence on

\footnotetext{
the measurement accuracy are of second order importance as compared to whether the established research output is divided by nine or sixteen.

${ }^{26}$ See, for example, Ursprung (2003).

${ }^{27}$ More important than the rank is of course the numerical value of the variable on which the ranking is based. In this respect ratings are more meaningful than rankings.
} 
our measure of research productivity. The ranking presented in column $\mathrm{C}$ of Table 4 therefore adjusts for these field-specific differences in publication behavior by aligning the field-specific means. This ranking is still closely correlated to the former ones: the rank-correlation coefficients amounting to $96.5 \%$ and $96.3 \%$, respectively. Now we observe however quite a few larger deviations in individual rankings. Nevertheless, the group of leading departments does not change as compared to the baseline rankings.

Thus far our rankings were based on orderings of individual scientists within narrow peer groups. One could argue that relying exclusively on actual data of relatively small cohorts may, in some cases, bias the evaluation of individual scientists and thereby give rise to unfair rankings. If, for example, unusually many first-rate scientists happen to be of approximately the same age, scientists who have the "bad luck" to be their contemporaries appear to be mediocre even when their overall research record is quite good, simply because they are compared only to their immediate cohort peers who are, coincidentally, very good. This kind of bias can be avoided by using (the exact version of) our formula presented in equation (3) - albeit at the cost of losing some information. The ranking presented in column $\mathrm{D}$ of Table 4 is based on the ranking of the respective faculty members according to our formula. Since the formula-based ranking in some instances does markedly differ from the baseline ranking that uses actual cohort data we conclude that the identified bias may have an undue effect even in the aggregate.

The last two rankings presented in Table 3 do not take the life cycle dimension of individual research productivity into account. They are based on a method that is similar to the method used by Combes and Linnemer (2003) in their "career" rankings, i.e. we compute the average research productivity of each department member and then either use the department-average of the respective percentile rankings (column E) or the 
average of the individual productivities (column F). ${ }^{28}$ Comparing these standard rankings with our baseline ranking demonstrates that life cycle effects are not only significant for the evaluation of individual scientists but also for the ranking of whole departments (the rank correlations between ranking $\mathrm{E}$ and $\mathrm{F}$ and ranking $\mathrm{A}$ amount to $94 \%$ and $88 \%$. Consider, for example, the department of the LMU. According to the standard ranking E, the LMU is ranked $6^{\text {th }}$ while according to our life-cycle rankings $\mathrm{A}$ and $\mathrm{B}$ it is ranked only $9^{\text {th }}$. This drop is apparently due to the fact that many of the most productive members of the LMU department are relatively young; neglecting the fact that young economists are in general more productive than older ones thus gives rise to an overestimation of the department's research standing. The cases of Frankfurt a.M., the two small departments of the RWTH Aachen and Lüneburg, and Erfurt are similar. The departments of the FU and HU Berlin, Mannheim, Bielefeld, Frankfurt a.O. and Osnabrück represent the counterpart category. These departments do significantly better when life cycle effects are taken into account. In these departments it is thus the old guard that is more productive - at least in relative terms.

The last ranking $(\mathrm{F})$ is more sensitive to outliers than ranking $\mathrm{E}$ because there is no upper bound for individual productivity. Extremely productive scientists thus give rise to a non-representative department average. Which of these two standard rankings is to be preferred depends of course on the context of the investigation. In any event, these two standard rankings clearly support our main argument: life cycle considerations also matter for research rankings of whole university departments.

The scatter diagram presented in Figure 6 neatly summarizes our main argument: life cycle considerations do matter for research rankings of university departments.

\footnotetext{
${ }^{28}$ To be more precise, we divide $\mathrm{R}_{\mathrm{i}}(\mathrm{t})$ as given in equation (2) by $\mathrm{t}+6$ in order to arrive at an average that takes pre-doctorate research into account.
} 


\section{Caveat for German readers}

Rankings are a delicate issue, especially if they concern us. We would therefore like to point out (in particular to our German readers) that we consider our study to be a contribution to the emerging field of scientometrics rather than an exercise in research evaluation. Research evaluations that are undertaken with the purpose of influencing managerial or policy decisions - especially if they are exclusively derived from bibliometric methods - need to be based on impeccable data sources. We neither have the inclination to become professional research evaluators nor do we have the means to assemble a data set that would satisfy the quality requirements for an evaluation suited for managerial or policy decisions. Our objective was to contribute to the body of scientometric literature dealing with the analysis of existing and the design of novel methods of research evaluation. The application of these methods cannot be the task of individual scientists; collecting and analyzing this kind of data on a regular basis should be left to institutions such as the German Science Council (see especially http://www.wissenschaftsrat.de/texte/6285-04-engl.pdf) and the recently established Institut für Forschungsinformation und Qualitätssicherung (http://www.dfg.de/ifq/).

Our rankings were thus devised to illustrate how professionally implemented research evaluations can allow for life cycle effects, i.e. these rankings are not the "real thing". We thus do not claim that our rankings necessarily reflect the relative research productivity of the ranked departments. Nevertheless, we believe that our results strongly indicate that life cycle effects are liable to have a significant influence on any ranking of research institutions. 
A substantial problem that we encountered in our attempt to provide a decent illustration of our main argument has been to compile faculty lists for a certain point of time and to assign the identified researchers to their respective cohort. In the appendix, we document the result of our efforts to overcome these problems that are, of course, not of a conceptual nature. Trickier, from a conceptual viewpoint, is the issue of how to deal with economists whose field is not adequately covered by the EconLit databank. Some econometricians and economic historians, in particular, are liable to be severely underrated by our approach, and this also may have a significant influence on the department rankings because of the small size of German economics departments. All of these problems can, however, be overcome, albeit at a cost that was not warranted by the purpose of our study.

Finally, we hope that the German system of higher education and research will develop institutions which will collect the kind of high quality data that is indispensable for conducting a rational research policy. If these hopes should be frustrated, the German economics profession is probably well advised to establish an information system of its own in order to stave off the dangerous influence of unsound evaluations that currently appear in the media on a regular basis. 


\section{References}

Backes-Gellner, U. and A. Schlinghoff (2004): Careers, incentives and publication patterns of US and German (business) economists, http://papers.ssrn.com/sol3/papers.cfm?abstract_id $=616822$

Baser, O. and E. Pema (2004): Publications over the academic life-cycle: Evidence for academic economists, Economics Bulletin 1, 1-8.

Bell, J. and J. Seater (1978): Publishing performance: Departmental an individual,” Economic Inquiry 16, 599-615.

Combes, P. and L. Linnemer (2003): Where are the economists who publish? Publication concentration and rankings in Europe based on cumulative publications, Journal of the European Economic Association 1, 1250-1308.

Coupé, T. (2003): Revealed performances: Worldwide rankings of economists and economics departments, 1991-2000, Journal of the European Economic Association 1, 1309-1345.

Coupé, T., V. Smeets and F. Warzynski (2003): Incentives, sorting and productivity along the career: Evidence from a sample of top economists, discussion paper, September 2003.

Dnes, A. and N. Garoupa (2005): Academic tenure, posttenure effort, and contractual damages, Economic Inquiry 43, 832-839.

Goodwin, T.H. and R.D. Sauer (1995): Life cycle productivity in academic research: Evidence from cumulative publication histories of academic economists, Southern Economic Journal, 728-743.

Frank, B. and G. Schulze (2000): Does economics make citizens corrupt? Journal of Economic Behavior and Organization 43, 101-113.

Grimes, P.W. and C.A. Register (1997): Career Publications and academic job rank: Evidence from the class of 1968, Journal of Economic Education 28, 82-92.

Hall, B., J. Mairesse and L. Turner (2005): Identifying age, cohort and period effects in scientific research productivity: Discussion and illustration using simulated and actual data on French physicists, NBER Working Paper No. 11739.

Hartley, J.E., J.W. Monks and M.D. Robinson (2001): Economists' publication patterns, The American Economist 45, 80-85.

Hutchinson, E.B. and T.L. Zivney (1995): The publication profile of economists, Journal of Economic Education, 59-79.

Kalaitzidakis, P., T. Mamuneas and T. Stengos (2003): Ranking of academic Journals and Institutions in Economics, Journal of the European Economic Association 1, 1346-1366.

Kenny, L. and R. Studley (1995): Economists' salaries and lifetime productivity, Southern Economic Journal 65, 382-393. 
Levin, S. and P. Stephan (1991): Research productivity over the life cycle: Evidence for academic scientists, American Economic Review 81, 114-132.

Moore, W., R. Newman and G. Turnbull (2001): Reputational capital and academic pay, Economic Inquiry 39, 663-671.

Oster, S.M. and D.S. Hamermesh (1998): Aging and productivity among economists, Review of Economics and Statistics 80, 154-156.

Rauber, M. and H. Ursprung (2005): Life cycle and cohort productivity in academic economic research: Evidence for Germany, mimeo, University of Konstanz.

Stephan, P. (1996): The economics of science, Journal of Economic Literature 34, 11991235.

Ursprung, H. (2003): Schneewittchen im Land der Klapperschlangen: Evaluation eines Evaluators, Perspektiven der Wirtschaftspolitik 2, 177-190, 2003. 
Figure 1

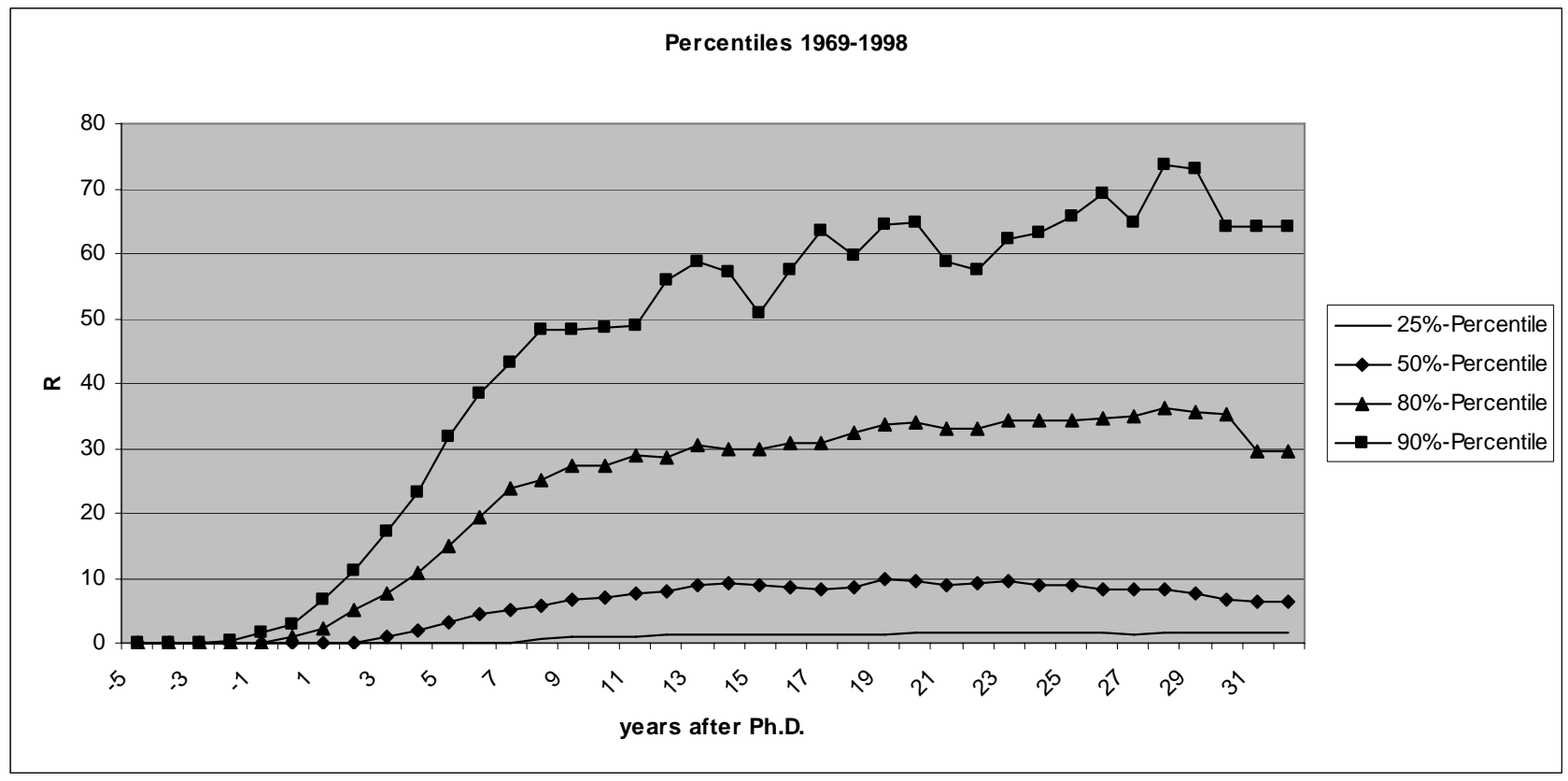




\section{Figure 2a}

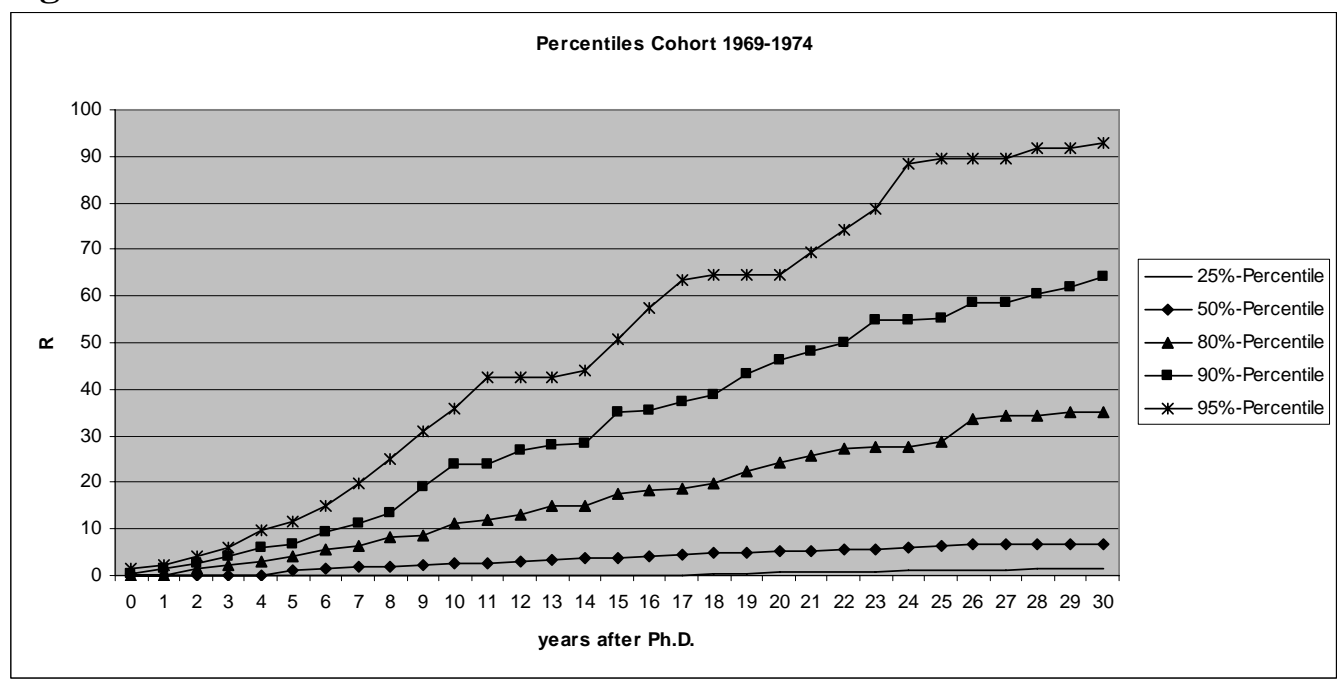

\section{Figure 2b}

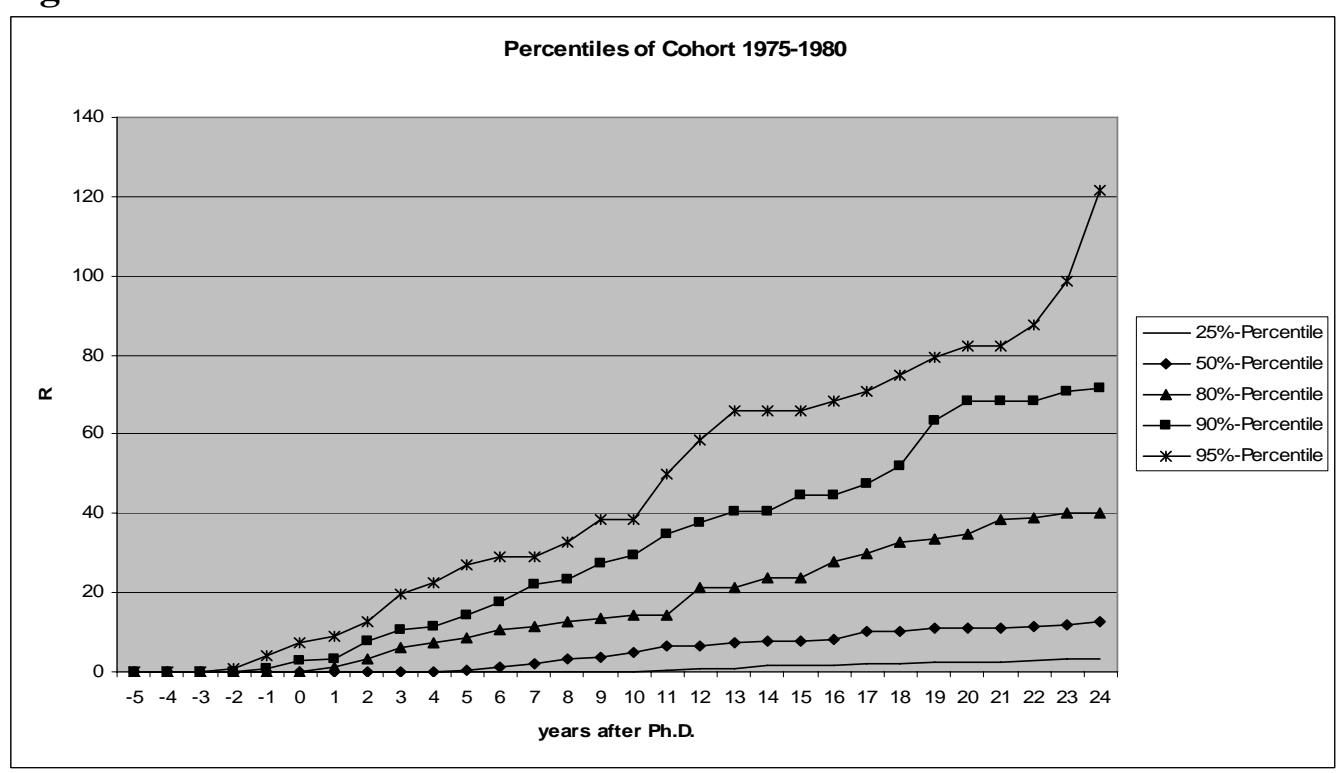

Figure 2c

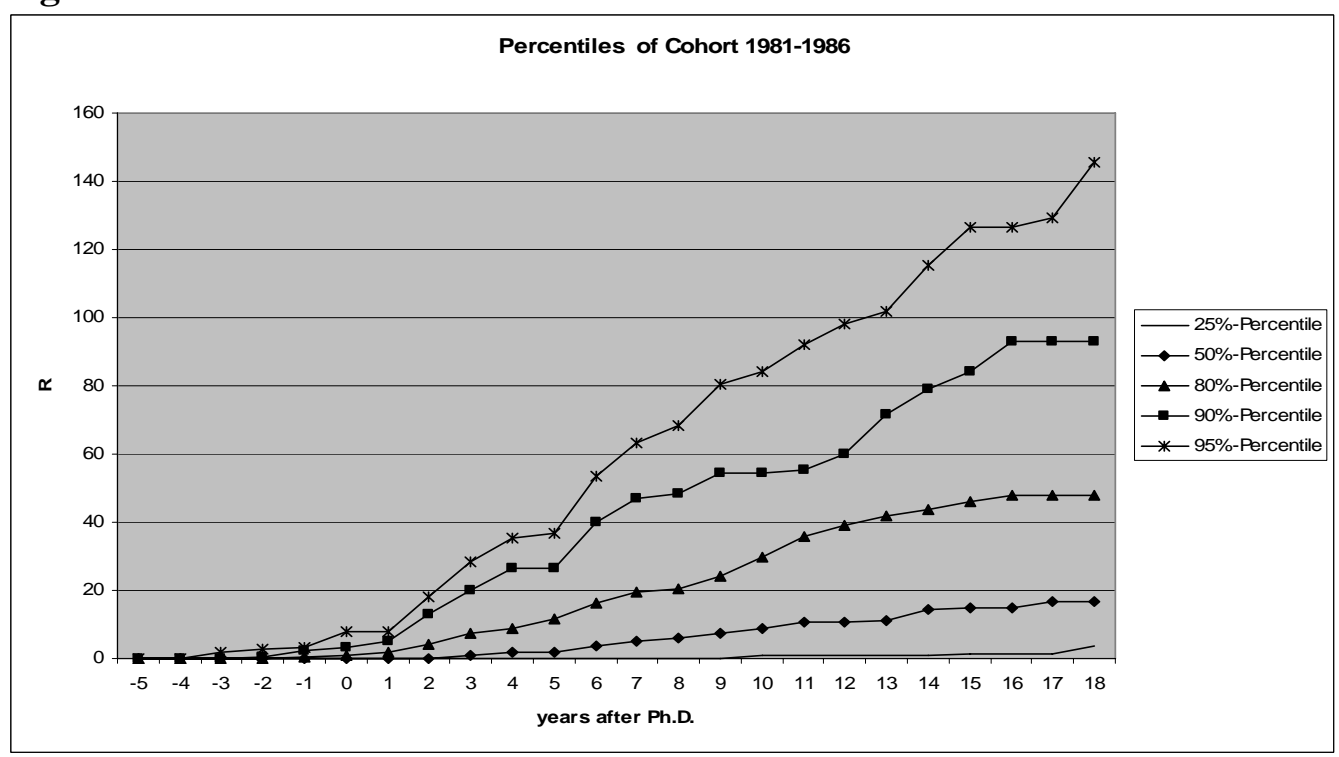




\section{Figure 2d}

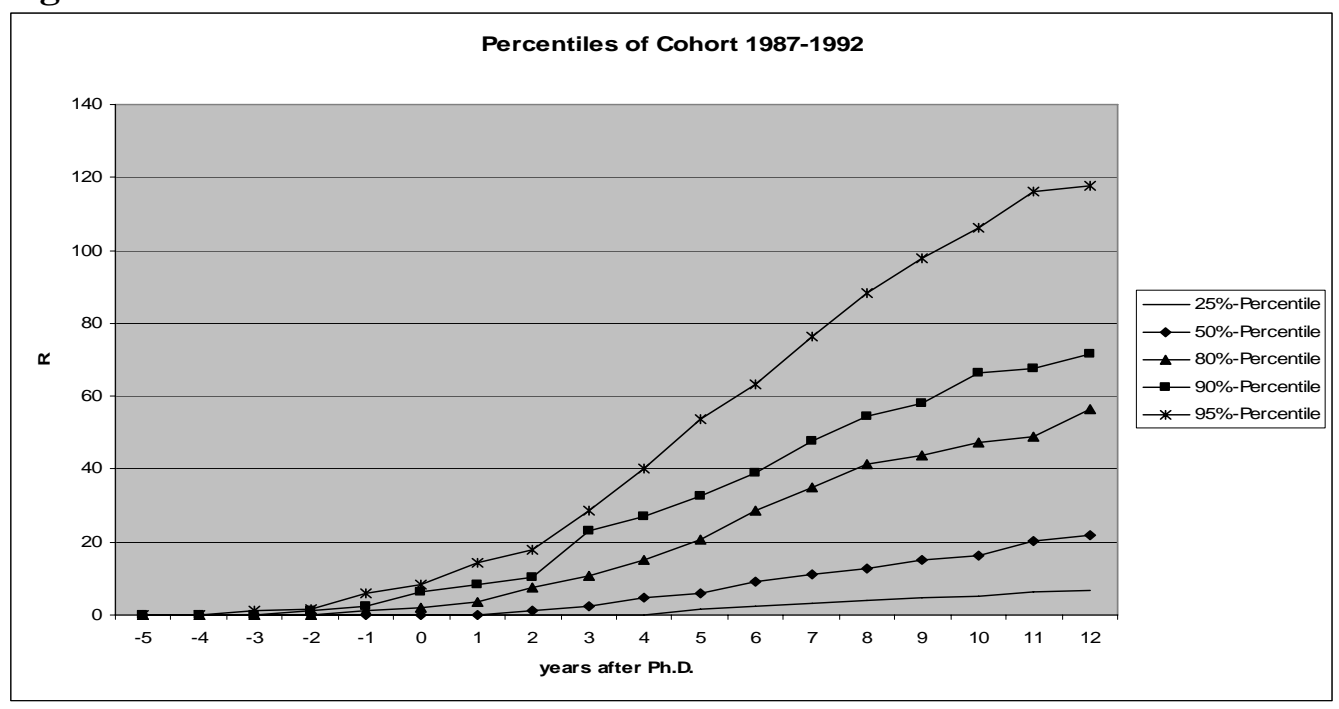

Figure 2e

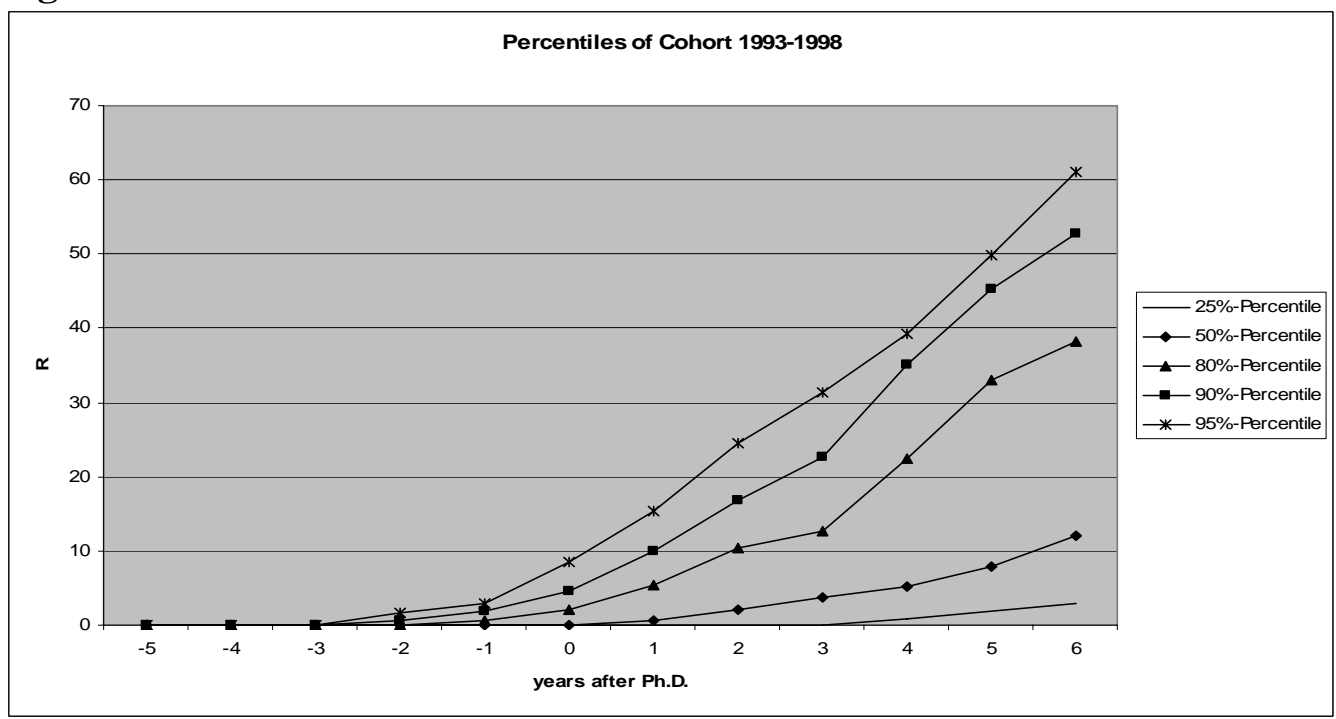

Figure 2f

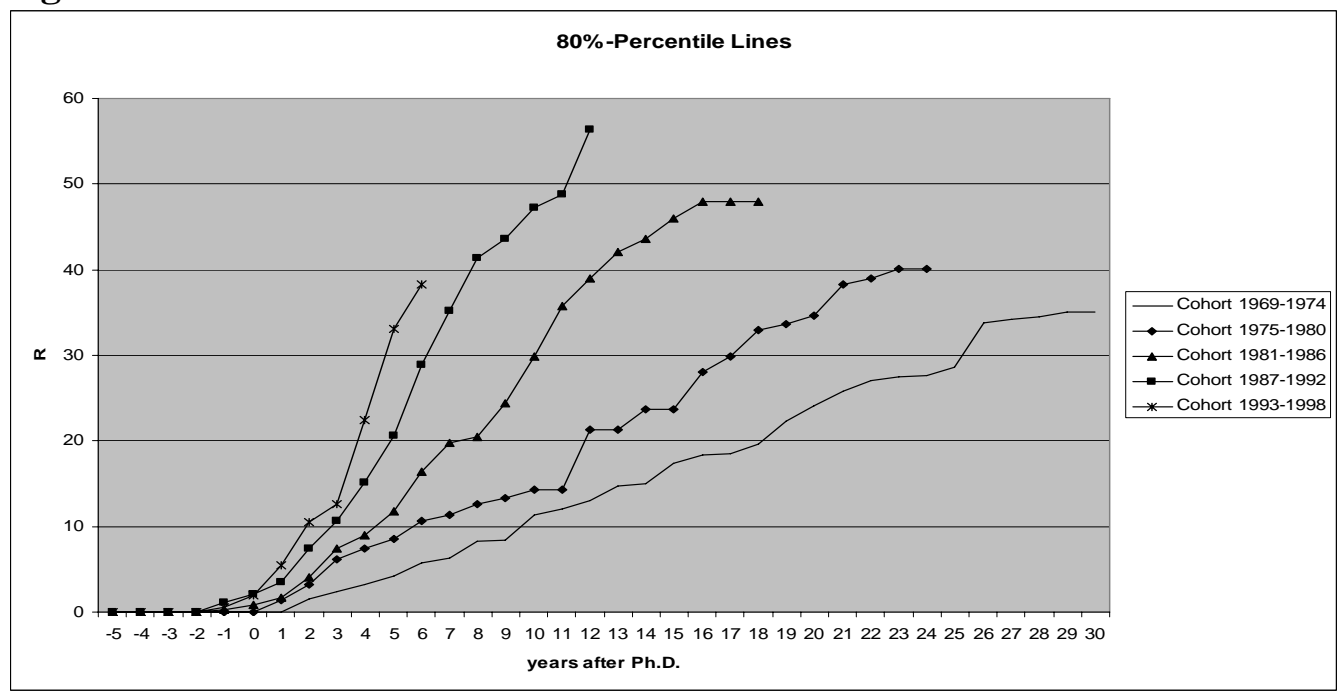




\section{Figure 3}

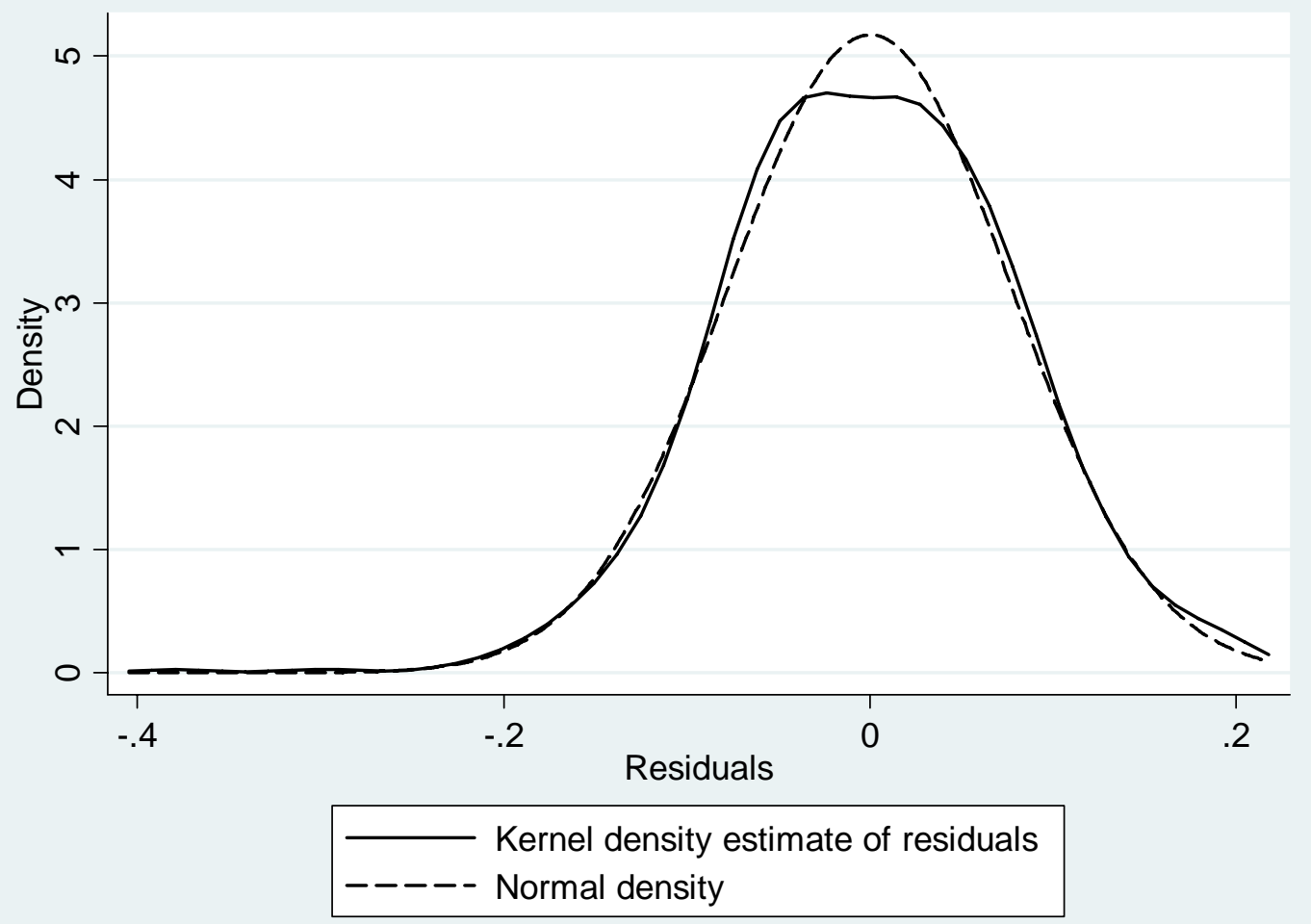


Table 1

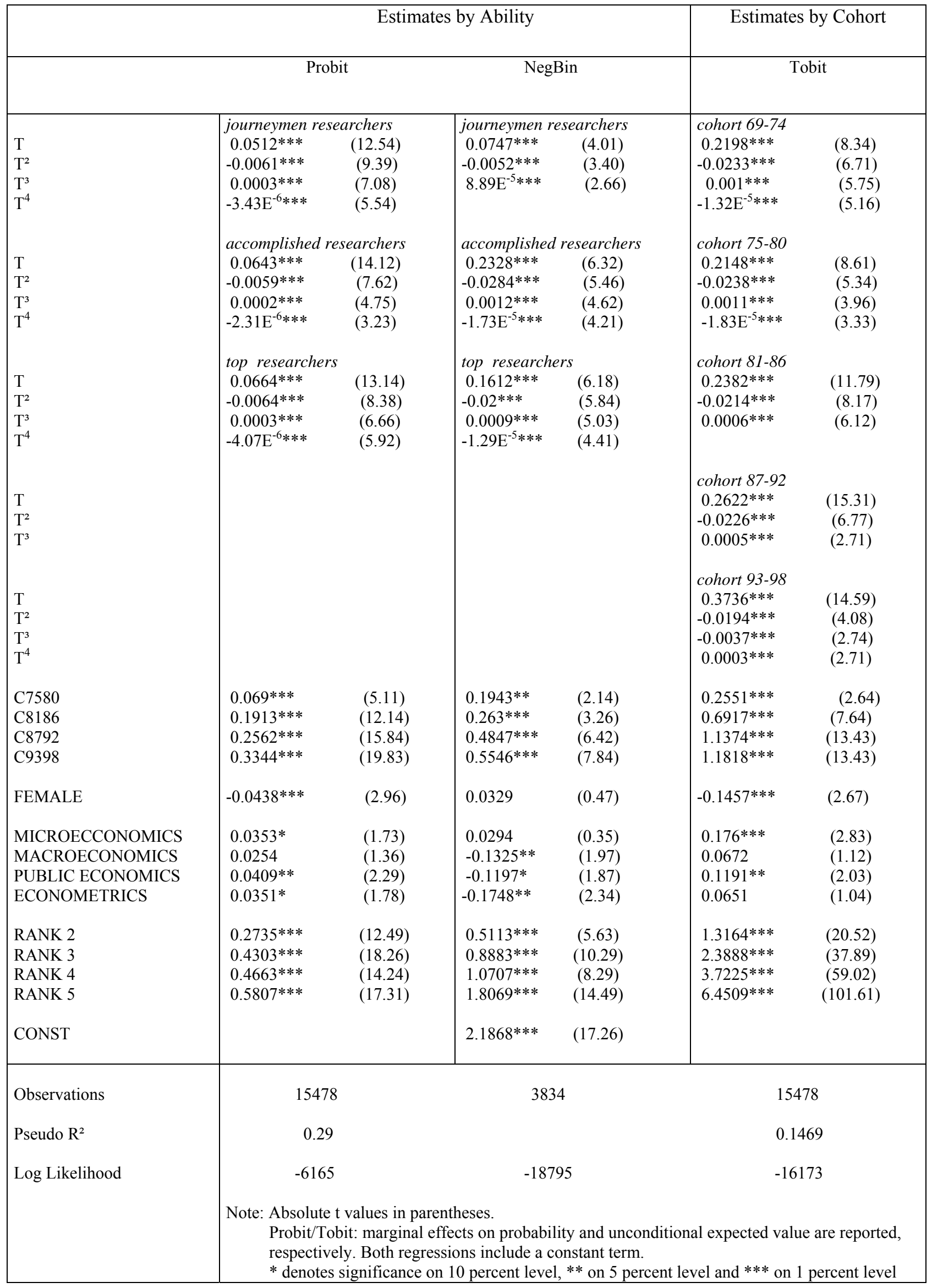


Figure 4a

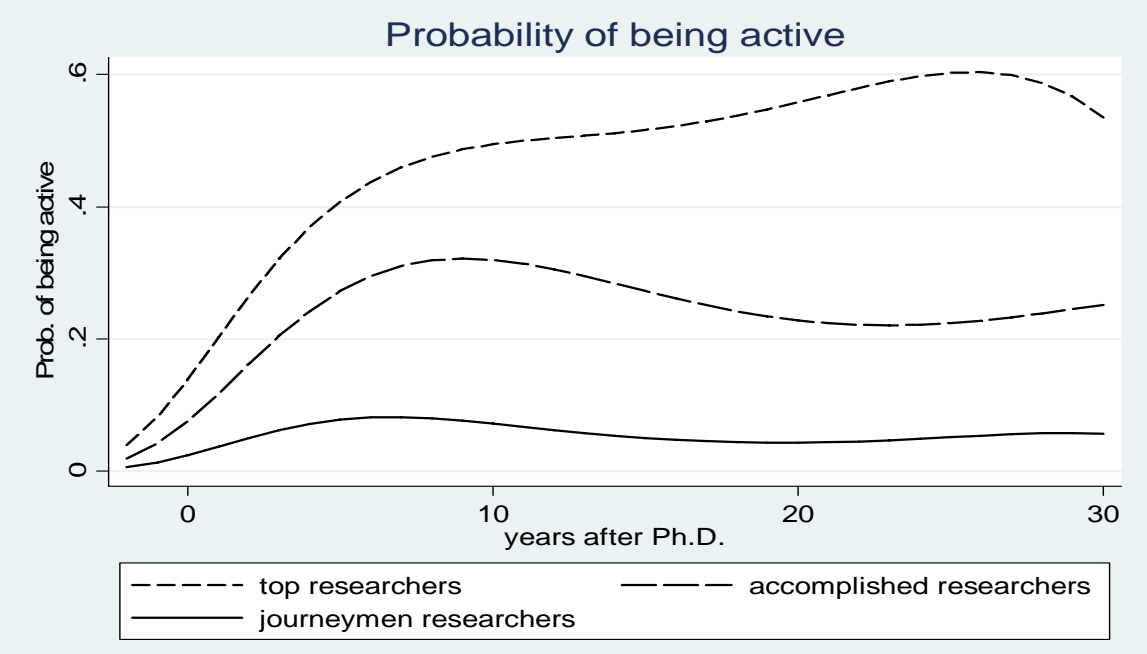

\section{Figure 4b}

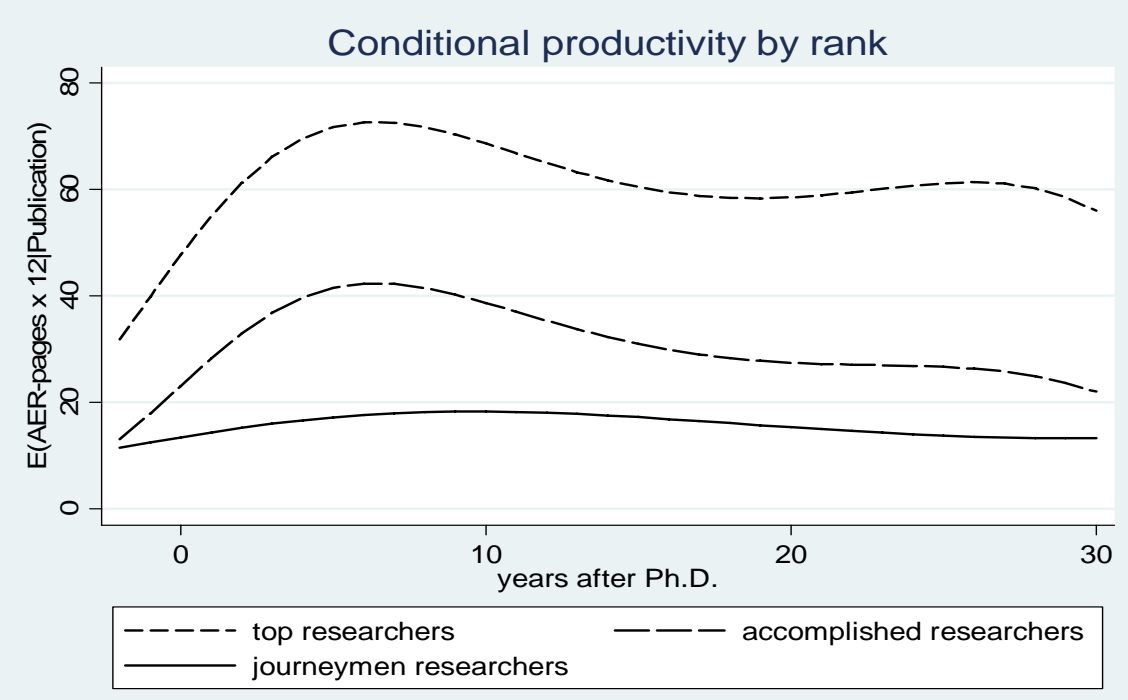

\section{Figure 5}

Tobit estimates by cohort (macro rank 4)

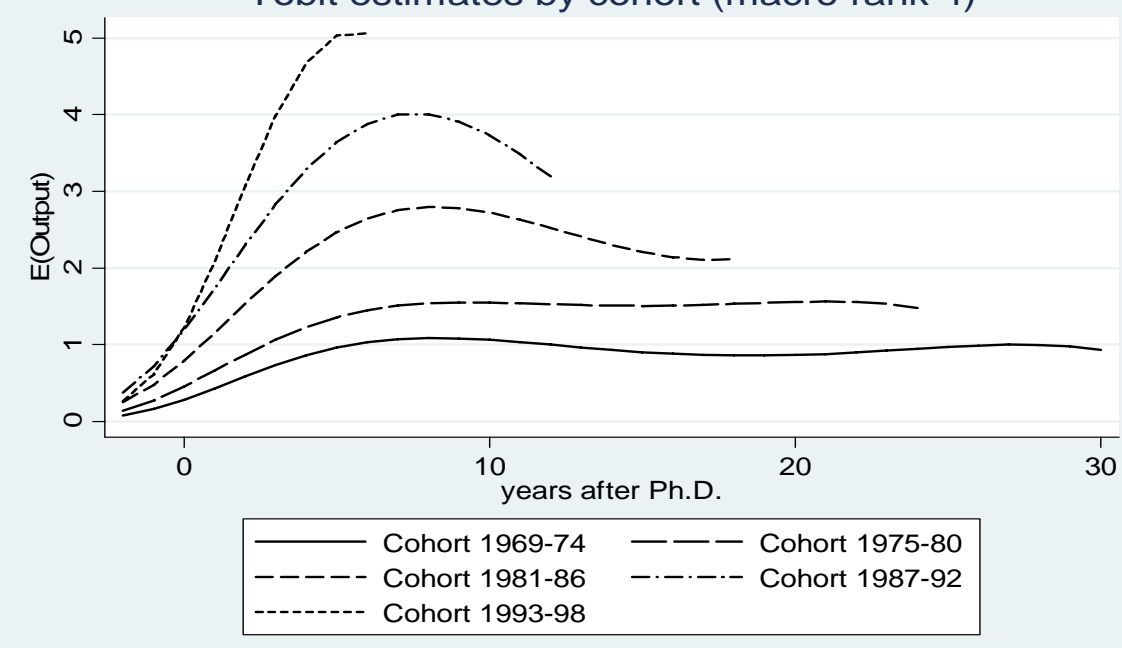


Table 2

Transition probabilities: year 6 -year 12

\begin{tabular}{|l|l|l|l|l|l|}
\hline & & $1 \& 2$ & 3 & 4 & 5 \\
\hline $1 \& 2$ & Coh.1 & $\mathbf{0 . 8 0}$ & $\mathbf{0 . 1 4}$ & $\mathbf{0 . 0 4}$ & $\mathbf{0 . 0 2}$ \\
& Coh.2 & 0.83 & 0.13 & 0.04 & 0.00 \\
\hline 3 & Coh.1 & $\mathbf{0 . 3 0}$ & $\mathbf{0 . 4 1}$ & $\mathbf{0 . 2 4}$ & $\mathbf{0 . 0 5}$ \\
& Coh.2 & 0.28 & 0.44 & 0.23 & 0.05 \\
\hline 4 & Coh.1 & $\mathbf{0 . 0 2}$ & $\mathbf{0 . 3 7}$ & $\mathbf{0 . 4 7}$ & $\mathbf{0 . 1 4}$ \\
& Coh.2 & 0.00 & 0.37 & 0.56 & 0.07 \\
\hline 5 & Coh.1 & $\mathbf{0 . 0 0}$ & $\mathbf{0 . 0 0}$ & $\mathbf{0 . 1 9}$ & $\mathbf{0 . 8 1}$ \\
& Coh.2 & 0.00 & 0.00 & 0.14 & 0.86 \\
\hline
\end{tabular}

Cohort A: 1969-1980

Cohort B: 1981-1992

Table 3

Transition probabilities of cohort B

\begin{tabular}{|l|l|l|l|l|l|}
\hline & & $1 \& 2$ & 3 & 4 & 5 \\
\hline $1 \& 2$ & $\mathbf{4 - 1 2}$ & $\mathbf{0 . 8 0}$ & $\mathbf{0 . 1 3}$ & $\mathbf{0 . 0 5}$ & $\mathbf{0 . 0 2}$ \\
& $6-12$ & 0.83 & 0.13 & 0.04 & 0.00 \\
& $8-12$ & 0.88 & 0.11 & 0.01 & 0.00 \\
\hline 3 & $\mathbf{4 - 1 2}$ & $\mathbf{0 . 3 0}$ & $\mathbf{0 . 3 9}$ & $\mathbf{0 . 2 6}$ & $\mathbf{0 . 0 5}$ \\
& $6-12$ & 0.28 & 0.44 & 0.23 & 0.05 \\
& $8-12$ & 0.24 & 0.62 & 0.14 & 0.00 \\
\hline 4 & $\mathbf{4 - 1 2}$ & $\mathbf{0 . 0 7}$ & $\mathbf{0 . 3 5}$ & $\mathbf{0 . 4 5}$ & $\mathbf{0 . 1 3}$ \\
& $6-12$ & 0.00 & 0.37 & 0.56 & 0.07 \\
& $8-12$ & 0.00 & 0.19 & 0.70 & 0.11 \\
\hline 5 & $\mathbf{4 - 1 2}$ & $\mathbf{0 . 0 0}$ & $\mathbf{0 . 0 2}$ & $\mathbf{0 . 1 9}$ & $\mathbf{0 . 7 9}$ \\
& $6-12$ & 0.00 & 0.00 & 0.14 & 0.86 \\
& $8-12$ & 0.00 & 0.00 & 0.12 & 0.88 \\
\hline
\end{tabular}

year 4 - year 12

year 6 - year 12

year 8 -year 12 
Table 4

\begin{tabular}{|c|c|c|c|c|c|c|c|c|c|c|c|c|}
\hline \multirow{3}{*}{$\begin{array}{l}\text { Uni } \\
\text { FU Berlin } \\
\end{array}$} & \multicolumn{8}{|c|}{ Life Cycle } & \multicolumn{4}{|c|}{ Standard } \\
\hline & \multicolumn{2}{|c|}{$\mathrm{A}$} & \multicolumn{2}{|c|}{$\mathrm{B}$} & \multicolumn{2}{|l|}{$\mathrm{C}$} & \multicolumn{2}{|l|}{$\mathrm{D}$} & \multicolumn{2}{|l|}{$\mathrm{E}$} & \multicolumn{2}{|l|}{$\mathrm{F}$} \\
\hline & 0.78 & 6 & 0.78 & 6 & 0.75 & 7 & 0.75 & 6 & 0.76 & 9 & 3.64 & 4 \\
\hline HU Berlin & 0.79 & 5 & 0.79 & 5 & 0.85 & 1 & 0.76 & 5 & 0.78 & 8 & 3.29 & 5 \\
\hline HWP Hamburg & 0.31 & 49 & 0.33 & 48 & 0.40 & 44 & 0.38 & 48 & 0.36 & 49 & 0.35 & 47 \\
\hline LMU München & 0.75 & 9 & 0.76 & 9 & 0.75 & 6 & 0.75 & 7 & 0.80 & 6 & 3.78 & 3 \\
\hline RWTH Aachen & 0.74 & 11 & 0.73 & 12 & 0.64 & 19 & 0.68 & 13 & 0.83 & 4 & 2.59 & 9 \\
\hline TU Berlin & 0.59 & 25 & 0.60 & 24 & 0.56 & 27 & 0.56 & 27 & 0.60 & 23 & 1.32 & 29 \\
\hline TU Chemnitz & 0.42 & 43 & 0.38 & 44 & 0.37 & 46 & 0.42 & 45 & 0.46 & 42 & 0.51 & 43 \\
\hline TU Dresden & 0.65 & 18 & 0.65 & 16 & 0.66 & 16 & 0.65 & 14 & 0.71 & 14 & 1.96 & 16 \\
\hline Uni Augsburg & 0.54 & 30 & 0.56 & 28 & 0.47 & 37 & 0.55 & 28 & 0.54 & 31 & 0.72 & 37 \\
\hline Uni Bamberg & 0.51 & 37 & 0.51 & 37 & 0.40 & 42 & 0.53 & 31 & 0.52 & 35 & 0.64 & 38 \\
\hline Uni Bielefeld & 0.77 & 7 & 0.77 & 7 & 0.71 & 10 & 0.73 & 9 & 0.72 & 11 & 2.11 & 13 \\
\hline Uni Bonn & 0.84 & 1 & 0.83 & 1 & 0.82 & 2 & 0.80 & 1 & 0.85 & 1 & 4.29 & 1 \\
\hline Uni Bremen & 0.37 & 46 & 0.35 & 47 & 0.43 & 40 & 0.37 & 50 & 0.27 & 51 & 0.22 & 50 \\
\hline Uni Dortmund & 0.74 & 10 & 0.74 & 11 & 0.74 & 8 & 0.70 & 11 & 0.71 & 12 & 2.38 & 12 \\
\hline Uni Duisburg-Essen & 0.39 & 44 & 0.41 & 43 & 0.40 & 45 & 0.42 & 44 & 0.44 & 44 & 0.51 & 42 \\
\hline Uni Erfurt & 0.48 & 41 & 0.47 & 41 & 0.42 & 41 & 0.50 & 38 & 0.59 & 25 & 1.68 & 20 \\
\hline Uni Erlangen-Nürnberg & 0.59 & 24 & 0.59 & 25 & 0.53 & 31 & 0.57 & 25 & 0.60 & 24 & 1.59 & 22 \\
\hline Uni Frankfurt / Main & 0.74 & 13 & 0.72 & 13 & 0.70 & 11 & 0.69 & 12 & 0.75 & 10 & 2.44 & 10 \\
\hline Uni Frankfurt / Oder & 0.77 & 8 & 0.76 & 10 & 0.69 & 12 & 0.71 & 10 & 0.71 & 13 & 1.76 & 18 \\
\hline Uni Freiburg & 0.52 & 33 & 0.52 & 33 & 0.56 & 29 & 0.51 & 35 & 0.54 & 32 & 1.27 & 30 \\
\hline Uni Gießen & 0.52 & 35 & 0.51 & 36 & 0.40 & 43 & 0.49 & 39 & 0.39 & 46 & 0.33 & 49 \\
\hline Uni Göttingen & 0.52 & 34 & 0.52 & 34 & 0.51 & 34 & 0.54 & 29 & 0.59 & 26 & 1.33 & 28 \\
\hline Uni Halle-Wittenberg & 0.49 & 40 & 0.50 & 39 & 0.51 & 33 & 0.46 & 41 & 0.47 & 40 & 0.60 & 41 \\
\hline Uni Hamburg & 0.52 & 32 & 0.53 & 32 & 0.57 & 26 & 0.51 & 34 & 0.54 & 33 & 1.21 & 31 \\
\hline Uni Hannover & 0.64 & 20 & 0.63 & 19 & 0.59 & 25 & 0.60 & 23 & 0.63 & 19 & 1.46 & 26 \\
\hline Uni Heidelberg & 0.59 & 23 & 0.59 & 26 & 0.65 & 18 & 0.63 & 16 & 0.57 & 29 & 2.99 & 7 \\
\hline Uni Hohenheim & 0.59 & 26 & 0.60 & 23 & 0.61 & 22 & 0.57 & 24 & 0.61 & 22 & 1.39 & 27 \\
\hline Uni Jena & 0.28 & 52 & 0.30 & 51 & 0.36 & 47 & 0.37 & 49 & 0.38 & 47 & 0.35 & 48 \\
\hline Uni Karlsruhe & 0.52 & 36 & 0.52 & 35 & 0.51 & 32 & 0.52 & 33 & 0.49 & 37 & 1.04 & 34 \\
\hline Uni Kiel & 0.81 & 3 & 0.82 & 2 & 0.78 & 5 & 0.79 & 3 & 0.84 & 2 & 2.93 & 8 \\
\hline Uni Köln & 0.56 & 27 & 0.57 & 27 & 0.47 & 36 & 0.56 & 26 & 0.51 & 36 & 1.14 & 33 \\
\hline Uni Konstanz & 0.82 & 2 & 0.82 & 3 & 0.82 & 3 & 0.79 & 4 & 0.84 & 3 & 3.17 & 6 \\
\hline Uni Leipzig & 0.33 & 48 & 0.32 & 49 & 0.32 & 48 & 0.38 & 47 & 0.37 & 48 & 0.39 & 46 \\
\hline Uni Lüneburg & 0.74 & 12 & 0.76 & 8 & 0.71 & 9 & 0.73 & 8 & 0.81 & 5 & 2.40 & 11 \\
\hline Uni Magdeburg & 0.64 & 19 & 0.62 & 20 & 0.62 & 20 & 0.61 & 21 & 0.69 & 15 & 1.47 & 25 \\
\hline Uni Mainz & 0.66 & 16 & 0.65 & 18 & 0.66 & 15 & 0.62 & 19 & 0.62 & 21 & 1.84 & 17 \\
\hline Uni Mannheim & 0.80 & 4 & 0.80 & 4 & 0.81 & 4 & 0.79 & 2 & 0.78 & 7 & 3.92 & 2 \\
\hline Uni Marburg & 0.49 & 39 & 0.49 & 40 & 0.45 & 38 & 0.53 & 32 & 0.55 & 30 & 2.02 & 14 \\
\hline Uni Münster & 0.44 & 42 & 0.43 & 42 & 0.48 & 35 & 0.45 & 42 & 0.48 & 38 & 0.73 & 36 \\
\hline Uni Oldenburg & 0.63 & 21 & 0.62 & 21 & 0.62 & 21 & 0.62 & 20 & 0.63 & 20 & 1.99 & 15 \\
\hline Uni Osnabrück & 0.69 & 14 & 0.69 & 14 & 0.67 & 14 & 0.63 & 18 & 0.57 & 28 & 0.87 & 35 \\
\hline Uni Paderborn & 0.30 & 50 & 0.31 & 50 & 0.24 & 51 & 0.36 & 51 & 0.33 & 50 & 0.22 & 51 \\
\hline Uni Passau & 0.53 & 31 & 0.54 & 30 & 0.53 & 30 & 0.51 & 36 & 0.53 & 34 & 1.14 & 32 \\
\hline Uni Potsdam & 0.55 & 28 & 0.54 & 31 & 0.59 & 24 & 0.50 & 37 & 0.47 & 39 & 0.64 & 39 \\
\hline Uni Regensburg & 0.65 & 17 & 0.65 & 17 & 0.69 & 13 & 0.63 & 17 & 0.65 & 18 & 1.55 & 24 \\
\hline Uni Rostock & 0.38 & 45 & 0.36 & 46 & 0.25 & 49 & 0.41 & 46 & 0.42 & 45 & 0.61 & 40 \\
\hline Uni Siegen & 0.55 & 29 & 0.55 & 29 & 0.56 & 28 & 0.53 & 30 & 0.58 & 27 & 1.56 & 23 \\
\hline Uni Stuttgart & 0.36 & 47 & 0.38 & 45 & 0.18 & 52 & 0.44 & 43 & 0.44 & 43 & 0.47 & 45 \\
\hline
\end{tabular}




\begin{tabular}{|l|c|c|c|c|c|c|c|c|c|c|c|c|}
\hline Uni Trier & 0.30 & 51 & 0.29 & 52 & 0.25 & 50 & 0.31 & 52 & 0.24 & 52 & 0.13 & 52 \\
\hline Uni Tübingen & 0.67 & 15 & 0.67 & 15 & 0.65 & 17 & 0.63 & 15 & 0.68 & 16 & 1.71 & 19 \\
\hline Uni Würzburg & 0.60 & 22 & 0.60 & 22 & 0.60 & 23 & 0.61 & 22 & 0.67 & 17 & 1.67 & 21 \\
\hline UniBW Hamburg & 0.51 & 38 & 0.50 & 38 & 0.44 & 39 & 0.48 & 40 & 0.46 & 41 & 0.49 & 44 \\
\hline
\end{tabular}
A: Life Cycle 3 years
B: Life Cycle 5 years
C: Life Cycle 3 years with field correction (mean $+3 /-3$ years)
D: Formula
E: Standard Approach: ranking within total Dataset
F: Standard Approach: simple average of productivity

Table 5: Rank Correlations

\begin{tabular}{|c|c|c|c|c|c|c|}
\hline & A & B & C & D & E & F \\
\hline A & 1.000 & 0.996 & 0.965 & 0.980 & 0.942 & 0.879 \\
\hline B & 0.996 & 1.000 & 0.963 & 0.982 & 0.949 & 0.874 \\
\hline C & 0.965 & 0.963 & 1.000 & 0.948 & 0.914 & 0.879 \\
\hline D & 0.980 & 0.982 & 0.948 & 1.000 & 0.959 & 0.923 \\
\hline E & 0.942 & 0.949 & 0.914 & 0.959 & 1.000 & 0.936 \\
\hline F & 0.879 & 0.874 & 0.879 & 0.923 & 0.936 & 1.000 \\
\hline
\end{tabular}

\section{Figure 6}

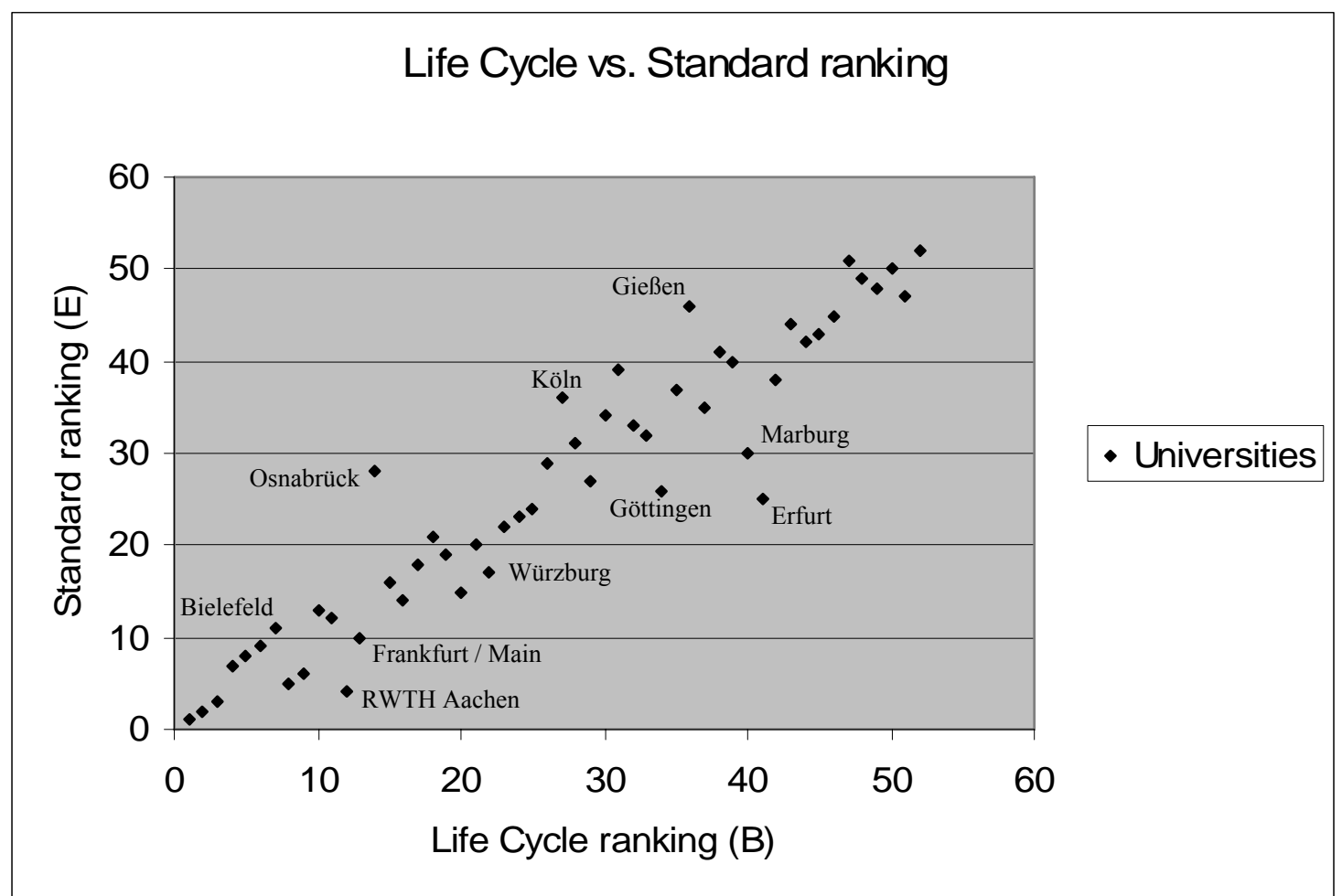




\section{Appendix: Employed faculty lists (end of 2004)}

We are grateful to the following colleagues for helping us to update the CHE faculty lists.

Brigitte Arnold; Lutz G. Arnold; Ansgar Belke; Siegfried Berninghaus; Charles B. Blankart; Friedel Bolle; Uwe Cantner; Michael Carlberg; Giacomo Corneo; Barbara Dluhosch; Malcolm Dunn; Udo Ebert; Bernhard Eckwert; Wolfgang Eggert; Frank C. Englmann; Hans Fehr; Lars P. Feld; Stefan Felder; Bernd Fitzenberger; Clemens Fuest; Hans Gersbach; Laszlo Goerke; Joachim Grammig; Hans Peter Grüner; Heinz-Dieter Hardes; Philipp Harms; Andreas Haufler; Carsten Hefeker; Fritz Helmedag; Manfred J. Holler; Stefan Homburg; Mathias Kifmann; Ingo Klein; Dorothea Kübler; Stefan Lang; Wolfgang Leininger; Jürgen Meckl; Renate Ohr; Michael Pflüger; Michael Rauscher; Winfried Schmähl; Günther Schulze; Joachim Schwalbach; Johannes Schwarze; Urs Schweizer; Christian Seidl; Helmut Seitz; Peter von der Lippe; Gert G. Wagner; Joachim Wagner; Rolf Walter; Bernd Wilfling; Matthias Wrede

bold print: these professors were omitted in the rankings because we have not been able to determine in which year they received their doctoral degrees.

FU Berlin: Baßeler, Ulrich; Berger, Helge; Bester, Helmut; Collier, Irwin L.; Corneo, Giacomo; Jaeger, Klaus; Konrad, Kai A.; Steiner, Viktor; Tomann, Horst; Wolters, Jürgen

HU Berlin: Blankart, Charles B.; Burda, Michael C.; Härdle, Wolfgang; Kamecke, Ulrich; Kemfert, Claudia; Lütkepohl, Helmut; Ritschl, Albrecht; Röller, Lars-Hendrik; Rönz, Bernd; Uhlig, Harald; Wickström, Bengt-Arne; Wolfstetter, Elmar

HWP Hamburg: Bechler, Ekkehard; Daviter, Jürgen; Größl, Ingrid; Hajen, Leonhard; Heise, Arne; Knapp, Ulla; Mattfeld, Harald; Schilling, Reiner; Schoeller, Wolfgang; Schui, Herbert

LMU München: Büttner, Thiess; Egger, Peter; Flaig, Gebhard; Haufler, Andreas; Huber, Bernd; Illing, Gerhard; Komlos, John; Marin, Dalia; Rady, Sven; Rees, Ray; Schlicht, Ekkehart; Schmidt, Klaus; Schnitzer, Monika; Sinn, Hans-Werner; Spree, Reinhard; Winter, Joachim

RWTH Aachen: Feess, Eberhard; Harms, Philipp; Lorz, Oliver; Wrede, Matthias

TU Berlin: Helberger, Christof; Henke, Klaus-Dirk; Kübler, Dorothea; Meran, Georg; Wagner, Gert G.; Wey, Christian

TU Chemnitz: Helmedag, Fritz; John, Klaus Dieter; Kuhn, Thomas

TU Dresden: Blum, Ulrich; Karmann, Alexander; Lehmann-Waffenschmidt, Marco; Schipp, Bernhard; Seitz, Helmut; Thum, Marcel; Wiesmeth, Hans

Uni Augsburg: Hanusch, Horst; Maußner, Alfred; Michaelis, Peter; Pfaff, Anita; Schittko, Ulrich; Welzel, Peter

Uni Bamberg: Meyer, Ulrich; Schmid, Michael; Schwarze, Johannes; Wenzel, Heinz-Dieter

Uni Bielefeld: Albers, Wulf; Böhm, Volker; Dawid, Herbert; Eckwert, Bernhard; Flaschel, Peter; Frohn, Joachim; Greiner, Alfred; Rosenmüller, Joachim; Semmler, Willi; Trockel, Walter

Uni Bonn: Breitung, Jörg; Imhof, Lorens; Merz, Monika; Moldovanu, Benny; Neumann, Manfred J.M.; Nöldeke, Georg; Riedel, Frank; Schweizer, Urs; Shaked, Avner; von Hagen, Jürgen

Uni Bremen: Biesecker, Adelheid; Elsner, Wolfram; Gerstenberger, Heide; Hickel, Rudolf; Huffschmid, Jörg; Kalmbach, Peter; Schmähl, Winfried; Sell, Axel; von der Vring, Thomas; Wohlmuth, Karl; Zachcial, Manfred

Uni Dortmund: Hoffmann, Mathias; Holländer, Heinz; Kraft, Kornelius; Krämer, Walter; Leininger, Wolfgang; Richter, Wolfram F.; Teichmann, Ulrich

Uni Duisburg-Essen: Amann, Erwin; Anker, Peter; Assenmacher, Walter; Cassel, Dieter; Clausen, Volker; Gaab, Werner; Heiduk, Günter S.; Paffenholz, Hans-Joachim; Pascha, Werner; Schnabel, Reinhold; Taube, Markus; Tietzel, Manfred; von der Lippe, Peter;

Uni Erfurt: Backhaus, Jürgen Georg; Königstein, Manfred; Rockenbach, Bettina; Rötheli, Tobias F.; Wegner, Gerhard; Winker, Peter; 
Uni Erlangen-Nürnberg: Harbrecht, Wolfgang; Klein, Ingo; Lachmann, Werner; Schnabel, Claus; Wambach, Achim; Wigger, Berthold U.

Uni Frankfurt / Main: Bauer, Tamás; Binder, Michael; Blonski, Matthias; Dunn, Malcom H.; Eisen, Roland; Fitzenberger, Bernd; Hassler, Uwe; Hujer, Reinhard; Klump, Rainer; Krüger, Dirk; Nautz, Dieter; Schefold, Bertram; Spahn, Paul Bernd; Walz, Uwe; Weichenrieder, Alfons J.; Wieland, Volker

Uni Frankfurt / Oder: Bolle, Friedel; Peters, Wolfgang; Ribegge, Hermann; Wagener, Hans-Jürgen

Uni Freiburg: Francke, Hans-Hermann; Gehrig, Thomas; Hauser, Siegfried; Knieps, Günter; Landmann, Oliver; Neumärker, Bernhard; Raffelhüschen, Bernd; Schulze, Günther G.; Vanberg, Viktor J.

Uni Gießen: Aberle, Gerd; Alexander, Volbert; Hemmer, Hans-Rimbert; Müller, Herbert; Rinne, Horst; Scherf, Wolfgang

Uni Göttingen: Berghoff, Hartmut; Bizer, Kilian; Gabisch, Günter; Klasen, Stephan; Ohr, Renate; Rübel, Gerhard; Schwager, Robert; Zucchini, Walter

Uni Halle-Wittenberg: Ahlert, Marlies; Becker, Claudia; Galler, Heinz; Hansjürgens, Bernd; Klein, Martin; Pies, Ingo; Pohl, Rüdiger; Steinmann, Gunter; Wenig, Alois

Uni Hamburg: Allgoewer, Elisabeth; Arnold, Bernhard; Funke, Michael; Hasenkamp, Georg; Hofmann, Hans-Joachim; Holler, Manfred; Lucke, Bernd; Maenning, Wolfgang; Pfähler, Wilhelm; Scheer, Christian; Schlittgen, Rainer; Scholing, Eberhard; Stahlecker, Peter; Straubhaar, Thomas; Tol, Richard S. J.; Wegscheider, Karl

Uni Hannover: Gerlach, Knut; Homburg, Stefan; Hübl, Lothar; Hübler, Olaf; Menkhoff, Lukas; Schmidt, Erich; Schmidt, Ulrich

Uni Heidelberg: Bell, Clive; Eichberger, Jürgen; Gans, Oskar; Gersbach, Hans; Kogelschatz, Hartmut; Leiner, Bernd; Oechssler, Jörg; Sangmeister, Hartmut

Uni Hohenheim: Ahlheim, Michael; Belke, Ansgar; Caesar, Rolf; Hagemann, Harald; Schwalbe, Ulrich; Spahn, HeinzPeter; Streb, Jochen; Wagenhals, Gerhard

Uni Jena: Cantner, Uwe; Freytag, Andreas; Grünärml, Frohmund; Kischka, Peter; Lorenz, Hans-Walter; Walter, Rolf; Windisch, Rupert

Uni Karlsruhe: Berninghaus, Siegfried; Bol, Georg; Egle, Kuno; Fuchs-Seliger, Susanne; Funke-Lambertz, Helmut; Grupp, Hariolf; Kowalski, Jan; Nakhaeizadeh, Rheza; Puppe, Clemens; Rachev, Svetlozar; Rothengatter, Werner

Uni Kiel: Bröcker, Johannes ; Lux, Thomas ; Raff, Horst; Requate, Till; Seidl, Christian; Snower, Dennis; Wohltmann, Hans-Werner

Uni Köln: Anderegg, Ralph; Baum, Herbert; Bomsdorf, Eckart; Donges, Jürgen; Eekhoff, Johan; Felderer, Bernhard; Feldsieper, Manfred; Fuest, Clemens; Funk, Peter; Kitterer, Wolfgang; Mosler, Karl; Ockenfels, Axel; Pierenkemper, Toni; Schellhaaß, Horst-Manfred; Schmid, Friedrich; Wied-Nebbeling, Susanne

Uni Konstanz: Breyer, Friedrich; Genser, Bernd; Kaas, Leo; Pohlmeier, Winfried; Schweinberger, Albert G.; Sturm, Jan Egbert; Ursprung, Heinrich W.

Uni Leipzig: Hasse, Rolf H.; Heilemann, Ullrich; Lange, Klaus; Lenk, Thomas; Paraskewopoulus, Spiridon; Vollmer, Uwe; Wiese, Harald

Uni Lüneburg: Heinemann, Maik; Merz, Joachim; Wagner, Joachim

Uni Magdeburg: Felder, Stefan; Gischer, Horst; Schöb, Ronnie; Schwödiauer, Gerhard; Weimann, Joachim

Uni Mainz: Bartling, Hartwig; Goerke, Laszlo; Kneip, Alois; Kolmar, Martin; Peffekoven, Rolf; Sauernheimer, Karlhans; Schulze, Peter; Tillmann, Georg; Weder di Mauro, Beatrice

Uni Mannheim: Börsch-Supan, Axel; Buchheim, Christoph; Conrad, Klaus; Franz, Wolfgang; Grüner, Hans Peter; Janeba, Eckhard; Kübler, Felix; Mammen, Enno; Schlieper, Ulrich; Schröder, Jürgen; Stahl, Konrad; Vaubel, Roland; von Thadden, Ernst-Ludwig; Wille, Eberhard

Uni Marburg: Feld, Lars P.; Fleischer, Karlheinz; Hayo, Bernd; Kerber, Wolfgang; Kirk, Michael; Korn, Evelyn; Röpke, Jochen; Schüller, Alfred

Uni Münster: Apolte, Thomas; Dieckheuer, Gustav; Grossekettler, Heinz; Hartwig, Karl-Hans; Krol, Gerd-Jan; Pfister, Ulrich; Prinz, Aloys; Ströbele, Wolfgang; Suntum, Ulrich van; Theurl, Theresia; Trede, Mark; Wilfling, Bernd 
Uni Oldenburg: Ebert, Udo; Scheele, Ulrich; Schüler, Klaus W.; Trautwein, Hans-Michael; Welsch, Heinz

Uni Osnabrück: Braulke, Michael; Gaertner, Wulf; Meyer, Bernd; Pauly, Ralf

Uni Paderborn: Gilroy, Bernard M.; Gries, Thomas; Liepmann, Peter; Nissen, Hans-Peter; Rahmann, Bernd; Reiß, Winfried

Uni Passau: Kleinhenz, Gerhard D.; Lambsdorff, Graf, Johann; Lüdeke, Reinar; Moosmüller, Gertrud; Pflüger, Michael

Uni Potsdam: Eickhof, Norbert; Fuhrmann, Wilfried; Jaeger, Carlo; Petersen, Hans-Georg; Schöler, Klaus; Strohe, Hans Gerhard

Uni Regensburg: Arnold, Lutz; Buchholz, Wolfgang; Hamerle, Alfred; Heubes, Jürgen; Jerger, Jürgen; Möller, Joachim; Wiegard, Wolfgang

Uni Rostock: Brümmerhoff, Dieter; Heilmann, Martin; Neuberger, Doris; Rauscher, Michael; Siebe, Wilfried; Tivig, Thusnelda

Uni Siegen: Franke-Viebach, Jan; Gemünd, Helmut; Hefeker, Carsten; Koch, Karl-Josef; Loef, Hans-Edi; Pethig, Rüdiger; Runde, Ralf

Uni Stuttgart: Englmann, Frank C.; Franke, Siegfried F.; Majer, Helge; Woeckener, Bernd

Uni Trier: Ambrosi, Gehrard Michael; Dickertmann, Dietrich; El-Shagi, El-Shagi; Flic, Wolfgang; Hardes, Heinz-Dieter; Hecheltjen, Peter; Knappe, Eckhard; Spehl, Harald

Uni Tübingen: Baten, Jörg; Buch, Claudia; Cansier, Dieter; Grammig, Joachim; Kohler, Wilhelm; Preuße, Heinz Gert; Stadler, Manfred; Starbatty, Joachim

Uni Würzburg: Berthold, Norbert; Bofinger, Peter; Fehr, Hans; Kukuk, Martin; Schulz, Norbert; von Collani, Erlat; Wälde, Klaus

UniBW Hamburg: Carlberg, Michael; Dluhosch, Barbara; Hackmann, Johannes; Kruse, Jörn; Meyer, Dirk; Reither, Franco; Schäfer, Wolf; Zimmermann, Klaus W. 